\title{
Skill effort: A new theoretical perspective on the relation between skills, skill use, mismatches, and wages
}

Citation for published version (APA):

van der Velden, R., \& Bijlsma, I. (2017). Skill effort: A new theoretical perspective on the relation between skills, skill use, mismatches, and wages. ROA. ROA Research Memoranda No. 005 https://doi.org/10.26481/umaror.2017005

Document status and date:

Published: 01/01/2017

DOI:

10.26481/umaror.2017005

Document Version:

Publisher's PDF, also known as Version of record

Please check the document version of this publication:

- A submitted manuscript is the version of the article upon submission and before peer-review. There can be important differences between the submitted version and the official published version of record.

People interested in the research are advised to contact the author for the final version of the publication, or visit the DOI to the publisher's website.

- The final author version and the galley proof are versions of the publication after peer review.

- The final published version features the final layout of the paper including the volume, issue and page numbers.

Link to publication

\footnotetext{
General rights rights.

- You may freely distribute the URL identifying the publication in the public portal. please follow below link for the End User Agreement:

www.umlib.nl/taverne-license

Take down policy

If you believe that this document breaches copyright please contact us at:

repository@maastrichtuniversity.nl

providing details and we will investigate your claim.
}

Copyright and moral rights for the publications made accessible in the public portal are retained by the authors and/or other copyright owners and it is a condition of accessing publications that users recognise and abide by the legal requirements associated with these

- Users may download and print one copy of any publication from the public portal for the purpose of private study or research.

- You may not further distribute the material or use it for any profit-making activity or commercial gain

If the publication is distributed under the terms of Article 25fa of the Dutch Copyright Act, indicated by the "Taverne" license above, 


\section{Skill effort: A new theoretical perspective on the} relation between skills, skill use, mismatches, and wages

Rolf van der Velden

Ineke Bijlsma

\section{ROA Research Memorandum}

ROA-RM-2017/5

Researchcentrum voor Onderwijs en Arbeidsmarkt | ROA

Research Centre for Education and the Labour Market | ROA 


\title{
Skill effort: A new theoretical perspective on the relation between skills, skill use, mismatches, and wages
}

\author{
Rolf van der Velden \\ Ineke Bijlsma \\ ROA-RM-2017/5* \\ May 2017
}

Research Centre for Education and the Labour Market

Maastricht University

P.O. Box 616, 6200 MD Maastricht, The Netherlands

$\mathrm{T}+31433883647 \mathrm{~F}+31433884914$

secretary-roa-sbe@maastrichtuniversity.nl

www.roa.nl

\footnotetext{
* The ROA Research Memorandum Series was created in order to make research results available for discussion, before those results are submitted for publication in journals.
} 


\section{Abstract \\ Skill effort: A new theoretical perspective on the relation between skills, skill use, mismatches, and wages**}

Mismatches between workers' skills and job demands have large negative effects on productivity, job satisfaction, and other outcomes. Current approaches to measure the impact of skills and skill mismatches on wages fail to specify the mechanism through which skills and mismatches may affect productivity. In this paper, we develop a new perspective by integrating skill proficiency and skill use into a new concept called skill effort. Skill effort is defined as a multiplicative function of skill proficiency and skill use. The intuitive understanding of this concept is that a skill can have no effect on productivity if it is not used and, vice versa, use of a skill is moderated by the skill proficiency level. The new concept is firmly rooted in use-it-or-lose-it, engagement, and self-efficacy theories and has a parallel in previous theories on performance. The theoretical breakthrough is that the concept of skill effort explicitly specifies the mechanism through which skills affect wages. Standard wage models (whether based on educational or skill variables) do not explicitly take this mechanism into account. In the skill effort model, skills can only affect wages if they are put to productive use. In the paper we show that this is indeed the case: there is no effect of proficiency level on wages, other than through the use of these skills.

In the paper we use this concept to develop a skill matching model using data on numeracy proficiency from the Programme for the International Assessment of Adult Competencies. We apply a realized matches approach to turn the skill effort model into three components: the effect of required skill effort, the effect of overperformance and the effect of underperformance. This model explains 29 of the variance in wages, which is much higher than the 23 found in alternative skill mismatch models. Moreover it not much lower than a standard educational mismatch model that explains 31 of the variance in wages. As education imparts more skills than just numeracy, this is in fact an indication that the developed skill mismatch model is very good. We discuss remaining issues on the measurement of this concept and present different ways to address them.

JEL classification: 126, J24

Keywords: skill proficiency, skill use, mismatch, wages

** This study was made possible by a grant from the Dutch Ministry of Education, Culture and Science. We thank Olivier Marie, Ken Mayhew, Seamus McGuinness, Dieter Verhaest, and participants of the 24th Workshop Transitions in Youth (September 3-5, 2015, Brno), the Sixth Workshop on Economics of Education (September 9-10, 2015, Barcelona), the 12th IHW/IAB Workshop on Labour Market Policies (October 12-13, 2015, Halle), the Second International PIAAC Conference (November 22-24, 2016, Haarlem), the DUHR seminar (January 26, 2016, Maastricht), the ROA Human Capital over the Life Cycle conference (February 19-20, 2016, Maastricht), and the OCW Kennislunch (March 3, 2016, The Hague) for useful comments and suggestions. 
Rolf van der Velden

Maastricht University

ROA

P.O. Box 616

NL-6200 MD Maastricht

The Netherlands

r.vandervelden@maastrichtuniversity.nl
Ineke Bijlsma

ROA

P.O. Box 616

NL-6200 MD Maastricht

The Netherlands

i.bijlsma@maastrichtuniversity.nl 


\section{Introduction}

Starting with the seminal work of Becker (1964), researchers have looked at the relation between schooling and productivity, typically using Mincerian wage regressions to assess the effect of schooling and experience on wages (Mincer, 1974). In these equations, schooling and experience are used as proxies for skills and wages as a proxy for productivity. These models are primarily supply driven and assume that individual productivity is a function of individual skills. With the large increase in higher education enrollment and the subsequent debate on overeducation, this human capital interpretation of the relation between schooling and productivity has been seriously challenged (Thurow, 1975; Freeman, 1976), leading to stronger emphasis on job characteristics determining productivity and focusing on the potential negative effects of overeducation (Bills, 2003). Several models and methods have been developed and tested (van der Velden and van Smoorenburg, 1997; Battu, Belfield, and Sloane, 2000; Hartog, 2000; Verhaest and Omey, 2006) and the general conclusion from the empirical evidence is that the effects of educational mismatches are best explained by matching models that assume that the combination of supply and demand determines productivity (Sattinger, 1993, 2012; Groot and Maassen van den Brink, 2000; Hartog, 2000; McGuiness, 2006). That is, productivity is highest when workers' educational level is a good match to the level required for their job. When workers' educational level is higher than the level required on the job, these workers still have a productivity benefit but not fully, since the utilization of their additional schooling in their work is restricted by job characteristics. Conversely, workers who lack some of the schooling required in their job will not reach the same productivity level as their co-workers with a matching educational level.

Although the empirical results of educational mismatches are quite consistent over time and across countries, to simply interpret these as skill mismatches has proven difficult (Halaby, 1994; Allen and van der Velden, 2001; Green and McIntosh, 2007; Quintini, 2011). This has been partly due to a lack of adequate measures of individual skills. The newly developed Programme for the International Assessment of Adult Competencies (PIAAC) from the Organization for Economic Cooperation and Development (OECD) has provided a first opportunity to look at educational mismatches and skills at the same time (Levels, van der Velden, and Allen, 2014).

Still, there are two major issues. One is that the standard wage model does not directly specify how skills can affect the productivity. In fact, the process through which skills affect productivity is treated as a black box. The second problem is that having information on skills possessed is not enough. To measure the effects of skill mismatches, we also need information on the skill requirements. The problem is that no large data set exists that contains direct information on these skill requirements. Instead, three approaches have been developed to proxy for skill requirements: 1) worker self-assessment (WS; asking the worker about the required level, e.g., by asking, "How important are the following skills for doing your current 
job?"), 2) realized matches (RM; taking the average or median skill level in an occupation as the required skill level), and 3) the job requirement approach (JRA; taking the use of skills in a job as a proxy for the required skill level). All of these approaches have their own weaknesses, both theoretically and empirically.

We develop a new perspective by integrating skill proficiency and skill use into a new concept called skill effort. Skill effort is defined as a multiplicative function of skill proficiency and skill use. The intuitive understanding of this concept is that a skill can have no effect on productivity if it is not used and, vice versa, use of a skill is moderated by the skill proficiency level. The new concept is firmly rooted in use-itor-lose-it, engagement, and self-efficacy theories and has a parallel in previous theories on performance. The theoretical breakthrough is that the concept of skill effort explicitly specifies the mechanism through which skills affect wages: Skills can only affect wages if they are put to productive use. In the paper we show that this is indeed the case: there is no effect of proficiency level on wages, other than through the use of these skills.

We apply this concept to develop a matching model based on RM using PIAAC data. We illustrate this for numeracy and perform robustness analyses using literacy. The model for numeracy explains $29 \%$ of the variance in wages, which is much higher than the $23 \%$ found in alternative skill mismatch models. Moreover it not much lower than a standard educational mismatch model that explains $31 \%$ of the variance in wages. As education imparts more skills than just numeracy, this is in fact an indication that the developed skill mismatch model is very good. We discuss remaining issues on the measurement of this concept and present different ways to address them.

\section{Earlier approaches to measure skill mismatches}

As indicated above, one problem in skill mismatch models is that direct information on the skill requirements on the job is lacking. Three approaches have been developed to construct a proxy of these skill requirements: WS, RM, and the JRA.

The WS approach typically asks the worker directly about the required level. The European Centre for the Development of Vocational Training European Union Skills Survey, ${ }^{1}$ for example, asks the question, "On a scale from 0 to 10, how important are the following skills for doing your current job?," followed by a list of skills. Similar approaches are used in many surveys among graduates (e.g., the REFLEX survey; see Allen and van der Velden, 2011). One of the major problems with this approach is that the answer scales lack an objective anchor (Allen and van der Velden, 2005) and are prone to social bias ("talking up one's job"). The anchoring problem has been addressed in several surveys by introducing clear anchors in the scale

1. See http://www.cedefop.europa.eu/en/publications-and-resources/publications/8088. 
(e.g., the O*NET survey ${ }^{2}$ ) or by using vignettes (King, Murray, Salomon, and Tandon, 2004; King and Wand, 2004). In addition, the social bias problem has been addressed by focusing on activities and using time intensity or frequency scales instead of importance or skill level, as in the JRA-for example, in the British Skills Survey (Green, Felstead, and Gallie, 2013) or the PIAAC survey (OECD, 2013a, 2013b). Still, neither problem has been completely solved (see later on the JRA).

A different version of the WS asks workers to indicate a skill mismatch directly. The European Working Conditions Survey, ${ }^{3}$ for example, asks workers, "Which of the following alternatives would best describe your skills in your own work?," with answers 1) "I need further training to cope well with my duties," 2) "My present skills correspond well with my duties," and 3) "I have the skills to cope with more demanding duties." The problem with this approach is, again, that it is prone to social bias (people may overestimate their own skill level). Apart from that, there is no separate estimate of the required skill level. This is all the more serious, because we know that part of the educational mismatches are just apparent and do not reflect a skill mismatch at all (Allen and van der Velden, 2001; Green and McIntosh, 2007; Quintini, 2011). This is because the lower skilled of a certain educational level are sorted into jobs that are less complex. These people may be formally "overeducated" for these jobs but, in fact, these jobs match their skills quite well. Levels et al. (2014) found evidence that this is indeed the case, especially in countries with low labor market regulation.

The second approach to assess skill requirements and skill mismatches is the RM approach. This approach takes the average or median skill level in an occupation as the required skill level and defines a worker as overskilled or underskilled if the worker has a skill proficiency level of - usually—one or one and a half standard deviations above or below that occupation-specific level. For example, Perry, Wiederhold, and Ackermann-Piek (2014) used PIAAC data to assess the average skill level of each International Standard Classification of Occupations (ISCO) two-digit occupation category in Austria, Germany, and the United States (leaving out those occupations with fewer than 30 observations). A more complex model was applied by Pellizari and Fichen (2013), also using PIAAC data. They used a sort of combination of the WS and RM approaches. First, they selected all workers who identified themselves as being well matched. For this, the authors used two questions from the PIAAC background questionnaire: "Do you feel that you have the skills to cope with more demanding duties than those you are required to perform in your current job?" and "Do you feel that you need further training in order to cope well with your present duties?" Only respondents who answered no to both questions (only approximately $20 \%$ of the workers) were considered well matched subjectively. The authors then assessed the range of skill proficiency levels of all the workers who identified themselves as well matched per country per one-digit ISCO occupation category. This range was then trimmed (omitting the lower and upper 5\%) and regarded as the "normal" skill range in that one-

2. See https://www.onetcenter.org/questionnaires.html\#generic.

3. See $\mathrm{http}: / / \mathrm{www}$.eurofound.europa.eu/publications/report/2012/working-conditions/fifth-european-working-conditions-surveyoverview-report. 
digit occupation category. Any worker - regardless of what he or she answered to the two subjective questions - is considered well matched if their skill proficiency levels fell in the country-occupation specific skill ranges. Anyone with a skill proficiency level above the $95 \%$ score was defined as overskilled and anyone below the 5\% range was defined as underskilled. Based on this model, $86 \%$ were defined as well matched, $10 \%$ were defined as overskilled, and only $3 \%$ were defined as underskilled in both the numeracy and literacy domains (Pellizari and Fichen, 2013).

One theoretical problem with the RM approach (not only here but also in the case of educational mismatches; see Battu et al., 2000; Hartog, 2000; Verhaest and Omey, 2006) is that the definition of well matched is always relative. Basically, the approach defines workers with an average or median skill proficiency level in a certain occupation as well matched. However, since there is no objective criterion that defines the actual required skill level, all of these workers may, in fact, be overskilled or underskilled. Assuming that the majority of workers will have a job that in fact matches their skills may not be a wild guess generally, but the RM approach typically ignores differences in skill mismatches across countries or across occupations (due to standardization per country and per occupation).

In addition, there is a statistical problem. Occupational categories are heterogeneous and contain occupations that could differ in required skill levels. This, of course, tends to hold more at the aggregated level of one-digit ISCO occupation categories than at the more disaggregated four-digit levels. The basic issue here is that workers in a one-digit ISCO occupation category could be wrongfully classified as matched or mismatched, although the required skill level at a more detailed level would suggest differently. The problem is that, in surveys such as PIAAC, sufficient observations are not usually available for assessing the average skill level at, for example, the three- or four-digit ISCO level in each country. Even the two-digit ISCO level is often not possible due to the small number of observations. This was one of the reasons why Pellizari and Fichen (2013) resorted to using skill proficiency levels at the one-digit ISCO level per country. However, these categories are far too heterogeneous to allow for a correct determination of whether a worker is well matched, overskilled, or underskilled.

The third approach, the JRA, was developed by Green et al. (2013) for the British Skills Survey and was also applied in the PIAAC survey. Instead of asking about the importance of a certain skill in a job, this approach asks about its time intensity or frequency of use. A typical question would be, "In your job, how often do you usually read letters, memos, or e-mails?" with answers ranging from never to every day (PIAAC; OECD, 2013b). A set of items relating to a certain skill domain, for example, literacy, and reflecting different complexity levels is then used to construct a scale on skill use. The interpretation of this scale is that it reflects the skill requirements on the job (hence the term job requirement approach). The assumption is that a high level of skill use reflects a higher level of required skills. Allen, Levels, and van der Velden (2013) have used this to construct a measure of skill mismatch that they call relative use of skill. 
Using PIAAC data, they standardized both measures of skill use and proficiency for a domain and then subtracted them. Workers with a skill use level one and a half standard deviations higher than what would have been predicted on the basis of their skill proficiency were classified as overusing their skills and workers with a level of skill use one and a half standard deviations lower than what would have been predicted on the basis of their skill proficiency level were classified as underusing their skills. In a strict sense, this concept of over- and underutilization only takes the perspective of the worker. Quite literally, overutilization from the worker's perspective implies that the person is using his or her skills more than the person's proficiency level would allow. That differs from a perspective in which the job is the reference: In this latter case, overutilization means that the job requirements are higher than the level a worker possesses.

A theoretical problem with the JRA is that the use of skills is not necessarily a good proxy for skill requirements. Moreover, the two concepts used to construct the mismatch variable, skill use and skill proficiency, are, in practice, closely linked, both empirically and theoretically. This makes it difficult to regard skill use an independent measure of skill requirement, since it also reflects skill proficiency. There is also a measurement problem in the JRA, as has been highlighted by Pellizari and Fichen (2013). Both constructs are measured on different scales. Standardizing both constructs actually disguises the fact that the two scales are fundamentally different. In that sense, the JRA suffers from the same problem of the definition of a good match as the RM approach: Both consider workers that have average skills compared to either the average use or the average in their occupation as being well matched, but that is not necessarily true.

\section{Toward a new theoretical model}

The assumption in the JRA that skill use and skill proficiency are different forces us to rethink both concepts. Can skill use be seen as a proxy for skill requirements or is it so closely related to skill proficiency that it is hard to disentangle the two? There are at least three strands of literature that suggest the latter: the use-it-or-lose-it theory, self-efficacy theory, and engagement theories.

The use-it-or-lose-it-theory (Mincer and Ofek, 1982; Bynner and Parsons, 1998; Krahn and Lowe, 1998; Salthouse, 2006; Desjardins and Warnke, 2012) argues that skills that are not being used depreciate over the life cycle. For example, Bynner and Parsons (1998) show that time out of paid employment is detrimental to numeracy skills. This result was less evident when looking at literacy skills. This is interpreted by the authors to mean that reading skills are more related to everyday life and so are still used upon employment cessation, whereas numeracy skills are much more related to work and are much less used in everyday life. Levels and van der Velden (forthcoming) used PIAAC data to document the factors that affect the acquisition and decline of skills over the life cycle. They concluded that the use of skills is 
strongly related to hampering or accelerating skill proficiency, although the causal direction is not quite clear. People may lose skills because they do not use them anymore or they may have stopped using them because they lost them.

Whatever the causal direction, self-efficacy and engagement theories suggest that the two concepts are closely interlinked. Self-efficacy theory, developed by Bandura (1977), states that task-related self-efficacy increases the likelihood of being engaged in a more challenging task, thus increasing the skill level and self-efficacy. Self-efficacy is one of the motivational variables that has been studied as one of the driving factors of engagement, which is a result of cognitive factors, motivational factors, as well as a positive attitude to use certain skills (Guthrie and Wigfield, 2000). In the conceptual foundation of skills surveys such as PIAAC, reading engagement and numeracy engagement are considered driving factors in the acquisition of these key skills (OECD, 2012a). Self-efficacy has been shown to be a good predictor of a range of academic outcomes (Multon, Brown, and Lent, 1991). Reading engagement and numeracy engagement have been shown to be closely linked to skill proficiency levels (OECD, 2012a).

If the concepts of skill use and skill proficiency are so closely linked, we need to rethink their relation to productivity. Are skill use and skill proficiency two sides of the same coin or are they different? Can they be seen as supplementary or as complementary? One of the driving questions challenging the human capital interpretation of the relation between skills and wages is why would employers pay for skills that are not required? We can pose a similar question for skill use: Why would employers pay for skills that are not used? All of the previous empirical work on the relation between skills and wages implicitly assumes that the wage premium for skills is related to using those skills on the job. If that is not the case, we would be back to a pure signaling or credential type of explanation (Spence, 1973; Collins, 1979), where employers are assumed to pay for schooling or skills that are not actually required on the job. Most of the empirical evidence, however, suggests that this is not the case (Hanushek and Woessmann, 2011; Hanushek, Schwerdt, Wiederhold, and Woessmann, 2014)

We believe that we need to develop a concept that firmly integrates skill proficiency and skill use into one new concept: skill effort. More specifically, we assume that productivity is a multiplicative function of two inputs: skills and effort. The intuitive understanding of this assumption is straightforward. Skills can affect productivity but only when they are put to use. ${ }^{4}$ There is no reward for skills that are not being used. This is in line with a basic human capital framework, assuming that there can only be a reward for skills that are actually used. Conversely, the effect of using a particular skill is moderated by the skill proficiency level. If the proficiency level is low, using that skill has less effect on productivity than when the proficiency level is high. The idea of regarding productivity as a multiplicative function of two inputs is not new. In the early

4. One can think of certain skills for which this relation is less straightforward. For example, a pilot needs to be very proficient in dealing with emergency situations and will also be rewarded for that type of skill, although it is not necessary that this skill be used often. This model therefore pertains to skills whose use is assumed to be central for functioning in a job. This is true for all key skills, such as numeracy, literacy, problem solving, and social skills. 
1960s, the psychologist Vroom (1964) developed expectancy theory in his study on the motivations for decision making. According to his theory, performance is a multiplicative function of ability and motivation. This theory has been applied and tested in different settings, mainly in education and in work. A recent review by van Iddekinge, Aguinis, and Mackey (2014) shows that the empirical research has provided mixed evidence, except in the case of job performance, where the results seem to support this theory.

We now express this as a formal model. Let us define the following:

$\mathrm{P}_{\mathrm{i}}=$ productivity level of individual $\mathrm{i}$

$\mathrm{W}_{\mathrm{i}}=$ wage level of individual $\mathrm{i}$

$\mathrm{S}_{\mathrm{i}}=$ skill proficiency of individual $\mathrm{i}$

$\mathrm{U}_{\mathrm{i}}=$ skill use of individual $\mathrm{i}$

$\mathrm{SE}_{\mathrm{i}}=$ skill effort of individual $\mathrm{i}$

$v_{i}=$ idiosyncratic error term

Then,

$\mathrm{P}_{\mathrm{i}}=\mathrm{W}_{\mathrm{i}}=\alpha+\beta \mathrm{S}_{\mathrm{i}} * \mathrm{U}_{\mathrm{i}}+\mathrm{v}_{\mathrm{i}}$ $=\alpha+\beta \mathrm{SE}_{\mathrm{i}}+v_{\mathrm{i}}$

To assess the effect of skill mismatches, we need to turn this equation into a standard matching model. We follow the conventional so-called overeducation-required education-undereducation model (ORU) developed by Duncan and Hoffman (1981). In this model, own schooling level (OS) is broken down into its three components:

- Years of required education (RE)

- Years of overeducation (OE), defined as OS - RE if OS > RE and zero otherwise

- Years of undereducation (UE) defined as RE - OS if OS < RE and zero otherwise

This means that $\mathrm{OS}=\mathrm{RE}+\mathrm{OE}-\mathrm{UE}$ and the standard wage regression is

$\mathrm{W}_{\mathrm{i}}=\alpha+\beta 1 * \mathrm{RE}_{\mathrm{i}}+\beta 2 * \mathrm{OE}_{\mathrm{i}}+\beta 3 * \mathrm{UE}_{\mathrm{i}}+v_{1}$

In other words, the ORU model assumes a wage premium for required years of schooling ( $\beta 1$ ), a wage premium for years of overeducation ( $\beta 2)$, and a wage penalty for years of undereducation ( $\beta 3$ ). Empirical findings around the world usually show that $\beta 1>\beta 2>1 \beta 31$ (Groot and Maassen van den Brink, 2000; Hartog, 2000; Levels et al., 2014). 
We can develop a similar model for skill mismatches. We assume that each occupation has a typically required level of skill effort. Workers can perform above or below these standards and will receive a wage premium/penalty accordingly. However, in line with the matching theories and the empirical results from educational mismatch research, there are decreasing returns/penalties to performing above or below the standard.

Let us assume that both $S_{i}$ and $U_{i}$ are both standardized variables with a mean of 10 and a standard deviation of one. ${ }^{5}$ Now let

$\mathrm{RSE}_{\mathrm{i}}=$ mean $\mathrm{SE}_{\mathrm{ij}}=$ typically required skill effort of individual $\mathrm{i}$ in occupation $\mathrm{j}$

$\mathrm{OSE}_{\mathrm{i}}=\left(\mathrm{SE}_{\mathrm{i}}-\mathrm{RSE}_{\mathrm{i}}\right)$ for $\left(\mathrm{SE}_{\mathrm{i}}-\mathrm{RSE}_{\mathrm{i}}\right)>0.5$, else $0=$ extent to which individual $\mathrm{i}$ has a higher skill effort (at least 0.5 standard deviations higher) than typically required in occupation $\mathrm{j}$

$\mathrm{USE}_{\mathrm{i}}=\left(\mathrm{RSE}_{\mathrm{i}}-\mathrm{SE}_{\mathrm{i}}\right)$ for $\left(\mathrm{RSE}_{\mathrm{i}}-\mathrm{SE}_{\mathrm{i}}\right)>0.5$, else $0=$ extent to which individual $\mathrm{i}$ has a lower skill effort (at least 0.5 standard deviations lower) than typically required in occupation $\mathrm{j}$

Now eq. (1) can be written as

$\mathrm{W}_{\mathrm{i}}=\alpha+\beta 1 * \mathrm{RSE}_{\mathrm{i}}+\beta 2 * \mathrm{OSE}_{\mathrm{i}}+\beta 3 * \mathrm{USE}_{\mathrm{i}}+v_{1}$

As in previous research, we expect the returns to required skill effort to be higher than the returns to overperformance in skill effort and these, in turn, to be higher (in absolute terms) than the returns to underperformance in skill effort.

\section{Data and method}

We use the PIAAC data set (OECD, 2013b) that assesses the proficiency of the adult population in key information-processing skills in OECD countries. The survey is designed to be cross-culturally and crossnationally valid. The original data set comprised 24 countries and approximately 166,000 respondents. The national samples are representative samples of non-institutionalized persons aged 16 to 65 years. Most countries have around 5,000 respondents in the sample, with the exception of Canada, which has more than 27,000 respondents. From this data set, we excluded Australia, because of data protection rules, and the Russian Federation, because we were not sure about the data quality. From the Canadian sample, we took a random sample of about $20 \%$ to avoid overrepresentation of the Canadian sample in the total data set.

5. A mean of 10 is used to avoid negative and zero values. The results are not sensitive to which positive value is used, as long as it is large enough so that negative or zero values are avoided. 
The PIAAC survey comprises a combination of computer-based assessment and-for those who are not able or willing to take the computer-based test-paper and pencil data collection strategies to assess the proficiency of respondents in three key information-processing skills: numeracy, literacy, and problem solving in technology-rich environments. We only focus on numeracy and check the comparability of the results for literacy. The reason for omitting problem solving is that around one-third of the respondents did not take the test because they lacked computer skills or chose to only use paper and pencil tests (which were not available for the problem solving domain). Moreover, some countries (Cyprus, France, Italy, and Spain) decided not to offer this test. Adaptive testing and item response techniques were used to calculate 10 plausible values (PVs) for each of these two domains. Together, these PVs for numeracy and literacy provide an unbiased estimate of the "real" score if the respondent would have taken all the numeracy- and literacy-related items (OECD, 2013b). The numeracy scale has a range from zero to 500, with an OECD international average of 273 and the literacy scale has a similar range, with an OECD average of 270.

The respondents were further interviewed on non-cognitive skills, key demographic and socioeconomic characteristics, as well as the extent to which they use key information-processing skills in the workplace or at home. For this paper, the key variables of interest are numeracy and literacy proficiency, as well as the use of these skills at work. The background questionnaire contained a number of questions related to the use of numeracy and literacy skills at work. We constructed two scales based on items that reflect the use of numeracy and literacy skills at work: six items on the use of numeracy skills at work (e.g., "In your job, how often do you usually a) calculate prices, costs, or budgets, b) use or calculate fractions, decimals, or percentages") and eight items on the use of reading skills ${ }^{6}$ at work (e.g., "In your job, how often do you usually a) read directions or instructions, b) read letters, memos, or e-mails"). We computed simple average scores for these sets of items. The Cronbach alphas for these two scales are 0.803 and 0.806 , respectively.

To estimate the average skill proficiency and skill use levels for each two-digit ISCO occupation category in the different countries, we use the calculations of Allen and Bijlsma (2015), who developed occupational profiles for each country (see Appendix A for details). This means that we have a country-specific estimate for the average skill proficiency level and the average level of skill use for all two-digit ISCO occupation categories in each of the two domains for all countries. At the individual level, we also use the scores for each of these four variables. For the proficiency scores, we use the average of the PVs for each domain. ${ }^{7}$ We now standardize these variables for each country separately with a mean of 10 and a standard deviation

6. The PIAAC questionnaire also has four items related to writing skills (e.g., "In your job, how often do you usually a) write letters, memos, or e-mails, b) write articles for newspapers, magazines, or newsletters"). Conceptually the reading items are closer to the domain of literacy, which is about understanding written information, which is why we decided not to use the writing items.

7. This was done for computational reasons. For the point estimates, this should not be a problem, but using the average of the 10 PVs can lead to underestimation of the standard errors. As a robustness check, we checked the results for several separate PVs to see whether they produce the same results. This is indeed the case (see Table B2 in Appendix B). Detailed results are available upon request. 
of one. The mean of 10 was chosen to avoid negative and zero values (see footnote 7). The skill effort measure and skill mismatch are then calculated using eqs. (1) and (3).

Next we selected male full-time working employees. This selection was made to avoid different wagesetting regimes for part-timers and women. In addition, the relation between skills and earnings for the selfemployed is quite different from that for employees. Full-time is defined as working 32 hours or more per week. We only selected respondents for whom we had valid information on skill proficiency, skill use, and hourly wages. Wages were trimmed per country, omitting the first and 99th percentiles of the respondents in each country.

The resulting data set includes 22 countries and 32,420 individuals. To avoid outliers in the distribution of skill proficiency per country-specific two-digit ISCO occupation category, we remove the first and 99th percentiles of the respondents in each occupation category per country. This leaves us with a working sample of 29,550 individuals. We use a multilevel model to account for the nested structure, allowing for error clustering at the country level. We estimate the following model:

$$
\begin{aligned}
\mathrm{W}_{\mathrm{ic}} & =\alpha_{\mathrm{c}}+\beta 1 \mathrm{~S}_{\mathrm{ic}} * \mathrm{U}_{\mathrm{ic}}+\beta 2 \mathrm{C}_{\mathrm{ic}}+v_{\mathrm{ic}}+\omega_{\mathrm{c}} \\
& =\alpha_{\mathrm{c}}+\beta 1 \mathrm{SE}_{\mathrm{ic}}+\beta 2 \mathrm{C}_{\mathrm{ic}}+v_{\mathrm{ic}}+\omega_{\mathrm{c}}
\end{aligned}
$$

where, for individual $\mathrm{i}$ in country $\mathrm{c}, \mathrm{W}_{\mathrm{ic}}$ is the natural logarithm of the hourly wages, ${ }^{8} \alpha_{\mathrm{c}}$ is a countryspecific constant, $\mathrm{S}_{\mathrm{ic}}$ is the skill proficiency level, $\mathrm{U}_{\mathrm{ic}}$ is the corresponding skill use, $\mathrm{SE}_{\mathrm{ic}}$ is the skill effort measure of eq. (1), $C_{i c}$ is a vector of control variables (with only the two variables age and age squared), and $v_{\text {ic }}$ and $\omega_{\mathrm{c}}$ are idiosyncratic error terms at the individual and country levels, respectively. We start the analyses with the numeracy proficiency level and the level of use of numeracy skills and later check whether similar results are obtained for literacy.

First we check the skill effort model with alternative specifications to check the validity of our assumption that productivity is a multiplicative function of skill and effort (proxied by skill use). We compare eq. (4) with a model in which we include the skill proficiency level and skill use level as separate effects, as well as a model in which we include both main effects and the interaction effect:

$$
\begin{aligned}
& \mathrm{W}_{\mathrm{ic}}=\alpha_{\mathrm{c}}+\beta 1 \mathrm{~S}_{\mathrm{ic}}+\beta 2 \mathrm{U}_{\mathrm{ic}}+\beta 3 \mathrm{C}_{\mathrm{ic}}+\mathrm{v}_{\mathrm{ic}}+\omega_{\mathrm{c}} \\
& \mathrm{W}_{\mathrm{ic}}=\alpha_{\mathrm{c}}+\beta 1 \mathrm{~S}_{\mathrm{ic}}+\beta 2 \mathrm{U}_{\mathrm{ic}}+\beta 3 \mathrm{~S}_{\mathrm{ic}} * \mathrm{U}_{\mathrm{ic}}+\beta 4 \mathrm{C}_{\mathrm{ic}}+v_{\mathrm{ic}}+\omega_{\mathrm{c}}
\end{aligned}
$$

8. The hourly wages are all adjusted for cross-national differences by a purchasing power parity conversion. 
If only the main effects in eq. (6) are significant, then the assumption that productivity is a multiplicative function of skill and effort must be rejected. If only the interaction term is significant, then our assumption is fully supported. When both main effects and the interaction effect are significant, we can conclude that the assumption is partly supported. One reason for this could be that the variable $S_{i c}$ (numeracy in this case) is also correlated with other cognitive skills (e.g., general cognitive ability), so that any remaining effect of $\mathrm{S}_{\mathrm{ic}}$ could reflect these other skills. This could also hold for $\mathrm{U}_{\mathrm{ic}}$.

Next we perform quantile regression analysis to check whether the effect of skill use is the same over the entire skill proficiency distribution and vice versa. Finally, we repeat the analyses for the literacy domain to see if we obtain the same results.

From eq. (5), we also derive information on whether or not both components $S_{\text {ic }}$ and $U_{\text {ic }}$ should have equal weights when calculating the skill effort measure. Remember that we started by standardizing both variables with a mean of 10 and a standard deviation of one, thus giving both components the same weight in the product term. However, if eq. (5) shows that the parameters $\beta 1$ and $\beta 2$ are different, we can adjust these weights to properly reflect the contribution of each component in the skill effort measure.

We next estimate the full model of skill effort match variables, using the three variables in eq. (3):

$\mathrm{W}_{\mathrm{ic}}=\alpha_{\mathrm{c}}+\beta 1 \mathrm{SEM}_{\mathrm{ic}}+\beta 2 \mathrm{C}_{\mathrm{ic}}+v_{\mathrm{ic}}+\omega_{\mathrm{c}}$

where $\mathrm{SEM}_{\mathrm{ic}}$ is a vector of the three skill effort match variables $\mathrm{RSE}_{\mathrm{ic}}, \mathrm{OSE}_{\mathrm{ic}}$, and $\mathrm{USE}_{\mathrm{ic}}$ from eq. (3). As a robustness check, we also estimate eq. (7) using the percentile rank in the country-specific wage distribution as a dependent variable. This is to check whether, in certain countries with a compressed wage distribution, the explained variance is better if we use the rank score rather than the logarithm of wages.

We conduct further robustness checks in Section 5 by splitting up the analysis for young, prime age, and older workers.

In the next model, we test whether the effects of the numeracy skill effort match variables are affected by skill effort match variables in other domains. First we test eq. (7) separately for the literacy domain and then add both domains in the model:

$\mathrm{W}_{\mathrm{ic}}=\alpha_{\mathrm{c}}+\beta 1 \mathrm{SEM}_{\mathrm{Lic}}+\beta 2 \mathrm{SEM}_{\mathrm{Nic}}+\beta 3 \mathrm{C}_{\mathrm{ic}}+v_{\mathrm{ic}}+\omega_{\mathrm{c}}$

where the subscripts $\mathrm{N}$ and $\mathrm{L}$ denote the numeracy and literacy domains, respectively. By comparing the results for literacy and numeracy from eq. (7) with those from eq. (8), we can see whether the parameter 
estimates are affected by including other skill domains. If the parameters of both models are substantially different, this implies that the parameters found in eq. (7) may be over- or underestimated.

Next, we include the coverage rate as an explanatory variable at the country level to see whether this explains cross-country variation in the effect of the skill effort match variables. The coverage rate is defined $^{9}$ as the number of employees covered by a collective agreement, divided by the total number of wage and salary earners in a country, based on OECD (2012b) data. The variable has a range of 13.6 to 99. ${ }^{10}$ We calculate cross-level interactions with the vector $\mathrm{SEM}_{\mathrm{ic}}$ as in the following model:

$\mathrm{W}_{\mathrm{ic}}=\alpha_{\mathrm{c}}+\beta 1 \mathrm{SEM}_{\mathrm{ic}}+\beta 2 \mathrm{CR}_{\mathrm{c}}+\beta 3 \mathrm{CR}_{\mathrm{c}} * \mathrm{SEM}_{\mathrm{ic}}+\beta 4 \mathrm{C}_{\mathrm{ic}}+v_{\mathrm{ic}}+\omega_{\mathrm{c}}$

where $\mathrm{CR}_{\mathrm{c}}$ is the country-specific coverage rate. We expect a general positive effect of $\mathrm{CR}_{\mathrm{c}}$ at the country level: A large proportion of workers falling under a collective wage agreement will increase the general wage level. On the other hand, we expect the interaction effects of $\mathrm{CR}_{\mathrm{c}}$ to have a depressing effect on the skill effort match variables $\mathrm{SEM}_{\mathrm{ic}}$. In other words, in countries where many workers fall under a collective wage agreement, wages are less affected by individuals' matching variables with respect to skill effort.

We also test a model in which we look at the effect of working in the public sector and its interaction effects on the skill effort match variables:

$\mathrm{W}_{\mathrm{ic}}=\alpha_{\mathrm{c}}+\beta 1 \mathrm{SEM}_{\mathrm{ic}}+\beta 2 \mathrm{PS}_{\mathrm{ic}}+\beta 3 \mathrm{PS}_{\mathrm{ic}} * \mathrm{SEM}_{\mathrm{ic}}+\beta 4 \mathrm{C}_{\mathrm{ic}}+v_{\mathrm{ic}}+\omega_{\mathrm{c}}$

where $\mathrm{PS}_{\mathrm{ic}}$ is a dummy indicating whether an individual is working in the public sector (PS).

Finally, we compare the new model with alternative models, as suggested by Allen et al. (2013), Pellizari and Fichen (2013), and a standard ORU model. The following alternative models are estimated:

$\mathrm{W}_{\mathrm{ic}}=\alpha_{\mathrm{c}}+\beta 1 \mathrm{~S}_{\mathrm{ic}}+\beta 2 \mathrm{U}_{\mathrm{ic}}+\beta 3 \mathrm{OU} \mathrm{U}_{\mathrm{ic}}+\beta 4 \mathrm{UU}_{\mathrm{ic}}+\beta 5 \mathrm{C}_{\mathrm{ic}}+v_{\mathrm{ic}}+\omega_{\mathrm{c}}$

where $\mathrm{OU}_{\mathrm{ic}}$ and $\mathrm{UU}_{\mathrm{ic}}$ are dummies denoting the overuse (OU) or underuse (UU) of skills according to Allen et al. (2013). Similarly, we estimate:

$\mathrm{W}_{\mathrm{ic}}=\alpha_{\mathrm{c}}+\beta 1 \mathrm{~S}_{\mathrm{ic}}+\beta 2 \mathrm{U}_{\mathrm{ic}}+\beta 3 \mathrm{OS} \mathrm{S}_{\mathrm{ic}}+\beta 4 \mathrm{US}_{\mathrm{ic}}+\beta 5 \mathrm{C}_{\mathrm{ic}}+v_{\mathrm{ic}}+\omega_{\mathrm{c}}$

9. See https://stats.oecd.org/glossary/detail.asp?ID=3554.

10. We also checked an alternative measure using the Employment Protection Legislation (EPL) from the OECD (2012c; see http://www.oecd.org/employment/emp). These results are not substantively different. However, we prefer the coverage rate to be the most theoretically relevant one. 
where $\mathrm{OS}_{\mathrm{ic}}$ and $\mathrm{US}_{\mathrm{ic}}$ are dummies denoting being overskilled (OS) or underskilled (US) according to Pellizari and Fichen (2013).

The alternative ORU model is the standard Duncan-Hoffman (1981) model in which we look at educational mismatches instead of skill mismatches:

$\mathrm{W}_{\mathrm{ic}}=\alpha_{\mathrm{c}}+\beta 1 \mathrm{RE}_{\mathrm{ic}}+\beta 2 \mathrm{OE} \mathrm{E}_{\mathrm{ic}}+\beta 3 \mathrm{UE}_{\mathrm{ic}}+\beta 4 \mathrm{C}_{\mathrm{ic}}+v_{\mathrm{ic}}+\omega_{\mathrm{c}}$

where $\mathrm{RE}_{\mathrm{ic}}$ denotes years of required education in occupation $\mathrm{j}$ in country $c,{ }^{11} \mathrm{OE}_{\mathrm{ic}}$ denotes years of overeducation (defined as own schooling $\mathrm{OS}_{\mathrm{i}}$ minus $\mathrm{RE}_{\mathrm{ic}}$ if $\mathrm{OS}_{\mathrm{i}}>\mathrm{RE}_{\mathrm{ic}}$ and zero otherwise), and $\mathrm{UE}_{\mathrm{ic}}$ denotes years of undereducation (defined as $\mathrm{RE}_{\mathrm{ic}}-\mathrm{OS}_{\mathrm{i}}$ if $\mathrm{OS}_{\mathrm{i}}<\mathrm{RE} \mathrm{E}_{\mathrm{ic}}$ and zero otherwise). Since education produces more skills than just numeracy (or literacy), we expect this ORU model to be better than the model in which we include only the skill effort match variables with respect to numeracy.

\section{Results}

First, we compare the skill effort model with alternative specifications to check the validity of the first assumption, namely, that productivity is a multiplicative function of skill and effort (proxied by skill use). We compare eq. (4) with a model in which we include the skill proficiency level and skill use level as separate effects (eq. (5)), as well as a model in which we include both the main effects and the interaction effect (eq. (6)). The results are displayed in Table 1.

$<$ Table 1 about here>

When only the main effects are entered in the model (eq. (5)), both numeracy proficiency and the use of numeracy skills show a positive significant effect on wages. A one standard deviation increase in numeracy skills raises wages by $13.2 \%$ and a similar increase in the use of numeracy skills raises wages by $9.3 \%$. This model (Model 1) explains $12.6 \%$ of the between-country variation $(=(0.119-0.104) / 0.119 * 100)$ and $28.9 \%$ of the within-country variation. However, with the inclusion of the interaction effect in eq. (6) (Model 2), these main effects are no longer significant and only the interaction effect is significant whereas the residual variation stays the same. Including only the interaction term as in eq. (4) (Model 3) hardly changes these parameters. This is very strong support for our assumption that states that productivity is a multiplicative function of skill and effort. Numeracy skills have no effect on wages other than through using these skills and, vice versa, the use of numeracy skills only affects wages in combination with some degree of proficiency.

11. We use Allen and Bijlsma's (2013) method to calculate the country-specific estimates of the required years of schooling per two-digit ISCO occupation category. 
As indicated, the parameters in eq. (5) (Model 1) show that numeracy proficiency affects wages more than using these skills does. The difference in effect size is about 1.5 to one. This result suggests that we need to readjust the weights of these components in the skill effort measure such that they correspond to this difference. This is done by setting the standard deviation of the skill proficiency variable to 1.5 instead of 1.0. The last column of Table 1 presents the results of eq. (4) using these adjusted weights. The results (Model 4) show that an increase of one standard deviation in numeracy skill effort yields a wage premium of $11.5 \%(=0.918 * 1.25 * 10)$.

$<$ Figure 1 about here>

Figure 1 shows the results of a robustness check using quantile regression analysis to assess whether the effect of skill use is the same over the entire skill proficiency distribution and vice versa. ${ }^{12}$ The results show that this is indeed the case: We see a plane surface with hardly any deviations.

In Table B1 of Appendix B we present the results of a robustness analysis using literacy scores instead of numeracy. We see that the main effects of skill proficiency and skill use become negative once the interaction term is introduced in Model 2 (eq. (6)). This can indicate multicollinearity of the three terms or some strange combination of low skill proficiency with high skill use or vice versa. More important is that the model with only the interaction term (Model 3) explains as much of the original variation as the model with only main effects (Model 1). We take this result as indicating that the concept of skill effort is robust over different domains.

$<$ Table 2 about here>

In Table 2, we present the results for skill effort matching as outlined in eq. (7), using the adjusted weights. ${ }^{13}$ As expected, we find required skill effort has a strong positive effect on wages. A one standard deviation increase in the required numeracy effort is associated with an increase of approximately $14 \%$ (= $1.129 * 1.25 * 10)$ in wages. Given the different weights for skill proficiency and skill use in determining skill effort, this wage increase is $60 \%$ driven by the skill proficiency component and $40 \%$ by the skill use component in the skill effort measure. Overperformance in skill effort is also positively rewarded, but not

12. Complete results are available upon request.

13. We also checked alternative specifications of the skill effort match variables, distinguishing between the different underlying components (skill proficiency and skill use). The main results are qualitatively the same and are available upon request. Table B2 shows the results if we use separate PVs instead of the average of the PVs. The results are substantially the same. Table B3 shows the results if we use a one standard deviation difference instead of 0.5 standard deviations to distinguish over- and underperformance in skill effort from the results for well-matched workers. The results are not significantly different. Given the fact that a 0.5 standard deviation difference within an occupation is quite large, we stick to the cutoff point of a difference of 0.5 standard deviations. Table B4 compares the skill effort matching model using the logarithm of wages with a model that uses the percentile rank in the country's wage distribution. The latter model does considerably worse if we compare the residual variance of the intercept model with the actual models. 
as much. Expending one standard deviation more skill effort on the job than is required yields a premium of $6.5 \%$, which is still considerable but less than the premium on required skill effort. As expected, underperformance in skill effort is penalized. Expending one standard deviation less skill effort on the job than is typically required is associated with a wage penalty of $7.3 \%$. This is just a little more, in absolute terms, as the positive effect of expending more skill effort on the job than is typically required.

If we compare these results with what is usually found in the educational mismatch literature, we see a strong similarity. The returns to required skill proficiency levels are greater than the returns to overperformance or underperformance in skill effort. However, contrary to the literature, we do not find that the wage penalty for the underperfomance of skill effort is less in absolute terms than the wage premium for the overperformance of skill effort. Instead, we find that the effect is more or less the same. This finding could be explained by the fact the results usually found for undereducation are obscured as the group of undereducated is selective and compensates for undereducation with skills acquired through experience. If we look at the skill effort as presented here, we observe a more linear relation between skill effort and productivity, with an additional premium for workers who perform at a matching skill effort level.

$<$ Figure 2 about here>

Figure 2 shows the explained variance of this model for the different countries plotted against the corresponding country's coverage rate. We note that the explained variance at the individual level differs quite markedly across countries, ranging from about $20 \%$ in the Slovak Republic and Estonia to approximately 50\% in the Netherlands and Austria, but there is no systematic relation with the coverage rate. We note that some countries that rank fairly high are typically regarded as occupational labor markets (Gangl, 2001), such as Austria, Germany, and the Netherlands, but others are typical flexible and internal labor markets, such as the United States and the United Kingdom. The countries that show the weakest relation between the skill effort match variables and wages are typical Eastern European transition economies and some Southern European countries, such as Italy and Spain. In Canada, wages are also much less strongly related to the skill effort match variables.

$<$ Figure 3 about here>

These results hardly change when we look at the percentile rank in the country's wage distribution, which might work better for countries with a compressed wage distribution. Figure 3 shows the results comparing the explained variances for each model (the full results are displayed in Table B4 of Appendix B). It shows that using the percentile rank in the country's wage distribution does not improve the model at all. All 
countries are well above the diagonal, although, for some countries, the difference is not great. The only country for which we see no difference is the Slovak Republic.

$<$ Figure 4 about here>

In Figure 4, we compare the cross-national variation in the explained variance for the skill effort matching model with the explained variance that we obtain from a simple ORU model. The two are highly correlated, meaning that most countries are close to the diagonal. This finding indicates that the low explained variance in the Eastern European countries is not driven only by a weak relation between skills and wages, but by a weak relation between schooling and wages as well. We interpret this finding to mean that, in well-functioning labor markets - whether typical occupational labor market types, such as the "Rheinland countries," or whether very open and flexible, such as the Anglo-Saxon countries-wages are primarily driven by skills and the use of these skills as expressed in our skill effort measure.

$<$ Table 3 about here>

In Table 3, we run the model for different age groups (16-34 years, 35-49 years, 50-65 years). The results indicate that the parameters are strongest for prime age workers (35-49 years) and older workers (50-65 years). For younger workers (16-34 years), all the estimates for required skill effort, as well as overperformance and underperformance in skill effort, are considerably lower. This result is consistent with previous work by Altonji and Pierret (2001), who showed that the wages of young workers are more affected by schooling variables, while the wages of prime age and older workers are more affected by actual skills. We generally see few differences between prime age and older workers, at least when we look at the rewards for overperformance or the penalties for underperformance, and these differences are not statistically significant. However, older workers do obtain a significantly higher wage premium for typically required skill effort compared to prime age workers (1.379 compared to 1.248).

$<$ Table 4 about here>

Table 4 compares the skill effort matching model for numeracy with a similar model for literacy, both separately and together. For comparison, column (1) repeats the estimates for the numeracy domain, as presented earlier in Table 2. Column (2) shows the estimates for the literacy domain separately. These follow the same pattern as the numeracy items, but always with slightly higher values, especially the rewards and penalties for over- and underperformance. The return to typically required literacy effort is 1.232 , compared to 1.129 for numeracy, corresponding to an approximately $9 \%$ difference. The difference in the returns to overperformance in literacy effort is greater ( 0.883 vs. 0.521$)$, an approximately $70 \%$ difference. The same also holds for underperformance in literacy effort. However, in a joint model (eq. (8), 
column (3)), the numeracy items clearly outweigh the literacy-related items, thus confirming previous results showing numeracy having a stronger effect on wages compared to literacy (Levels et al., 2014). The magnitudes of the effects are reduced by about $70-80 \%$ for the literacy items and only about $10-25 \%$ for the numeracy items. In the joint model, the effect of required literacy effort is almost half that of required numeracy effort: A one standard deviation increase in required literacy effort yields a wage premium of $5.0 \%$, whereas a similar increase in required numeracy effort yields a wage premium of $10.3 \%$. Similarly, overperformance in literacy effort by one standard deviation yields a wage premium of $2.3 \%$, compared to $5.8 \%$ in the case of numeracy effort. Conversely, underperformance of literacy effort by one standard deviation yields a wage penalty of $2.3 \%$, compared to $6.0 \%$ in the case of numeracy effort. We conclude that the effects of skill effort in the different domains are not simply additive: The skill effort in both numeracy and literacy overlaps, which leads to an overestimation of the effects of one skill domain if the other is not included as well. This result holds more strongly for the literacy domain than for the numeracy domain. We will take this into account when looking at the results of the following analyses, which focus on numeracy again.

Next, we continue with the numeracy skill effort matching model and include the country's coverage rate as well as interaction terms with the skill effort match parameters (eq. (9)). ${ }^{14}$ The coverage rate is only available for 19 of the 22 countries. The results are presented in Table 5 .

$<$ Table 5 about here>

The analysis shows some interesting results. First, we see that the coverage rate in itself has no significant effect. However, the coverage rate has a strong general positive effect once we include the cross-level interaction effects with the skill effort match variables. That is, a strong coverage rate increases overall wages when controlling for the skill effort match variables and the interactions with coverage rate. A $10 \%$ increase in the coverage rate increases wages in a country by about $8.2 \%$. However, this effect is offset by the negative interaction of the coverage rate with the skill effort match variables. The skill effort match variables show the effects of required skill effort and the over- and underperformance of skill effort in a situation when the coverage rate is zero. If we compare these results with the parameters of the skill effort matching model without the interaction effects with the coverage rate in these countries (column (2)), we see that all the parameters for the skill effort match variables are much larger for countries where the coverage rate is zero. For example, the effect of a one standard deviation increase in required skill effort in a country with a coverage rate of zero is $18.2 \%$, but this effect decreases by $0.6 \%$ for every $1 \%$ increase in the coverage rate, becoming a negative effect for countries with a coverage rate of $30 \%$ or more. We see similar depressing effects of the coverage rate on the returns to overperformance in skill effort $(b=-0.003)$ and a decreasing penalty for underperformance $(b=0.004)$.

14. An alternative model using the EPL is presented in Table B5 in Appendix B. The results are quite similar to those shown here, although the explained variance is a bit lower. For theoretical reasons, we prefer the coverage rate. 
$<$ Figure 5 about here>

This result is illustrated in Figure 5, which shows the different returns to required skill effort by coverage rate. We see a clear negative relation between the strength of the effect of required skill effort and the coverage rate, ranging from about 1.6 in the United States to about 0.8 in Sweden.

$<$ Table 6 about here>

In Table 6, we look at the effect of working in the public sector. Column (1) presents the results of the main effects model, including a dummy for working in the public sector in the skill effort matching model. The general wage penalty for working in the public sector is $11.0 \%$. However, it is clear that this penalty is not evenly distributed across the entire skill effort range. Column (2) provides the results of eq. (10), where interaction effects are added to the model. The general wage penalty for working in the public sector is now not significantly different from zero (-0.832). This means that workers in the public sector with zero skill effort obtain the same wages as similar workers in the private sector. However, the interaction effect with required skill effort is negative $(b=-0.106)$. This means that, for workers in an occupation where the typical required skill effort is average $(10 * 10=100)$, the wage penalty is $2.2 \%$. We can also see that working in the public sector depresses the positive effect of overperformance $(-0.040)$ and the negative effect of underperformance $(+0.062)$. Interestingly the effect of the latter is somewhat larger in absolute terms than the effect of the former: The penalties for underperformance in the public sector are less severe than similar punishments in the private sector.

$<$ Table 7 about here>

Finally, in Table 7, we show the results of our skill effort matching model and compare it with some other models. Column (1) shows the same parameters as in Table 2. Column (2) presents the results of the method of Allen et al. (2013), with the numeracy proficiency level, the skill use level, and dummies for the relative overutilization or underutilization of skills compared to skill proficiency levels. To compare the results, skill proficiency and skill use have the same scale as in the previous models (with a mean of 10 and standard deviations of 1.5 and 1.0, respectively). The results show the expected positive effects for skill proficiency and skill use. One standard deviation of extra skills yields a wage premium of $12.9 \%$ (= $8.58 * 1.5$ ) and one standard deviation of more use yields a wage premium of $9.8 \%$. The effect of the relative overuse of skills compared to the skill level is not significant; however, being overskilled relative to the use of skills (which is the same as the underuse of skills) has a significant positive effect. Note that the reference here is skill use on the job, which turns the parameter into a positive effect (like the effect of 
overeducation in the ORU model). Being overskilled compared to the use of skills pays off with a premium of about 3.2\%. Nevertheless, the model of Allen et al. (2013) performs less well than the previously introduced skill effort matching model. The percentage of explained variance of the model compared to that of the intercept model is much lower than for the skill effort matching model (22.6\% vs. 28.8\%). Column (3) shows similar results for the Pellizari-Fichen (2013) model. The return for a one standard deviation increase in skill proficiency is $15.7 \%$ and a similar increase in the use of numeracy skills incurs a wage return of $8.7 \%$. The penalty for being overskilled is $8.6 \%{ }^{15}$ and the wage premium for being underskilled is $10.7 \%$. Although these effects are all significant, the explained variance of the model is again lower than that of the skill effort matching model (22.9\% vs. $28.8 \%$ ). Finally, in column (4), we compare the skill effort matching model with a standard ORU model. To make the results more comparable to those of the skill effort matching model, we used the average years of schooling in an occupation as the proxy for required education (using the same algorithm as Allen and Bijlsma, 2015). The results show the familiar outcomes of an approximately $9.8 \%$ increase in wages for each additional year of schooling, a $3.1 \%$ increase in wages for each year of overschooling, and a similar wage penalty for each year of underschooling. Since education imparts more skills than just numeracy, we expected this model to do better than the skill effort matching model. This is indeed the case, but the difference is remarkably small: $31.0 \%$ versus $28.8 \%$. This is again strong support for the skill effort matching model, showing that wages are driven by a multiplicative function of skill proficiency and skill use.

\section{Problem of within-occupation heterogeneity}

As shown above, our approach of skill effort and associated mismatch indicators is superior to other approaches of measuring mismatches (Allen et al. 2013; Pellizari and Fichen, 2013) in terms of explaining wages. Moreover, the concept is theoretically more advanced and well rooted in other theoretical approaches. However, still, we are basically using an RM approach to assess the effect of skills mismatches, which implies that we are neglecting heterogeneity within occupational categories. Our RM approach uses the mean skill proficiency and skill use level in an occupation as an indicator of the typically required skill effort in that occupation. If occupational groups are very heterogeneous, this could lead to the incorrect assignment of workers as being matched or mismatched. In the previous analyses, we used country-specific estimates of the required skill effort in each two-digit ISCO occupation category. If we could use a more refined classification, such as a three- or even four-digit ISCO level, this could reduce the problem of within-occupation heterogeneity. Allen and Bijlsma's (2015) method of obtaining robust estimates using a multilevel model already stretches the possibilities of the current PIAAC data set to the limit and cannot be used to obtain estimates at the three- or four-digit level.

15. Remember that the reference here is the well-matched worker and not the required skill level, hence the reversal of signs. 
A very promising possibility is to use so-called small area estimation (SAE) models to arrive at more detailed estimates. The basic idea is to use other data sets in combination with the PIAAC data to obtain a more precise and reliable indicator of the required skill effort in detailed occupations. This method has been successfully used by Bijlsma, van den Brakel, van der Velden, and Allen (2017) to estimate literacy proficiency levels at a very detailed regional level (over 200 municipalities in the Netherlands). In this paper, we do the same to arrive at average skill effort levels at the one-, two-, and three-digit ISCO levels. For this, we use the Dutch Labour Force Survey (LFS) data and PIAAC data. The basic idea of SAE is to develop a prediction model on a smaller data set (PIAAC in this case) and use a larger data set (LFS in this case) with the same predictors to obtain a synthetic estimate of the dependent variable in each one-, two-, or three-digit ISCO occupation category. The outcome is a weighted sum of direct estimates (from PIAAC) and synthetic estimates where the weight is based on the precision of each of the two estimates. Appendix $\mathrm{C}$ describes the model we use. The results in Appendix $\mathrm{C}$ show that the standard errors can be considerably reduced by using SAE models instead of direct estimates, especially when there are fewer than 100 to 150 cases in an occupation. This is a first indication that the estimates of the average skill proficiency levels that we use for the two-digit ISCO occupation categories in each country are likely to be unstable in the case of low numbers of respondents. The robust estimators of Allen and Bijlsma (2013) provide more stable estimates but do not address the problem of within-two-digit-occupation heterogeneity. This heterogeneity is due to the fact that each two-digit ISCO occupation category is made up of different three-digit ISCO occupation categories. We can simulate the effect of aggregation by using SAE models to assess the average numeracy skill effort level at the one-, two-, and three-digit ISCO levels, respectively. Table 8 provides the results.

<Table 8 about here>

The results in Table 8 indicate that the effect of required skill effort increases significantly when a more refined classification is used. The effect of required skill effort almost doubles in magnitude when moving from the one-digit model to the three-digit model (from 1.393 to 2.237). In addition, using the three-digit ISCO level as a basis instead of the two-digit ISCO level (as in the current analysis) significantly increases the effect of required skill effort, from 1.943 to 2.237 , an increase of about $15 \%$. Put differently, if one uses broad occupational categories, such as one- or two-digit ISCO occupation categories, one will underestimate the effect of the required skill effort and overestimate the relative effect of performing better or worse than is typically required. There is no indication that the increase in the effects of required skill effort tapers off when moving from the two- to the three-digit model. This result suggests that even more precise estimates can be obtained when using an even more refined classification, such as a four-digit (or even more refined) classification. This means that the effects of required skill effort are likely to be underestimated in all RM models, while the effects of individual overperformance or underperformance in skill effort are likely to be overestimated in these models. 


\section{Conclusions}

There is convincing evidence that the wage effects of education are largely driven by skills (Hanushek and Woessmann, 2011; Hanushek et al., 2015), although the effects are weaker in less institutionalized settings (Levels et al., 2014) and the mechanism through which skills affect wages is largely left unexplained. There is also strong evidence of different returns in the case of educational mismatches (Hartog, 2000; Groot and Maassen van den Brink, 2000). Generally, workers gain more rewards for years of required education than for years of overeducation, while the penalties for years of undereducation are the least severe.

The research on skill mismatches has produced more mixed results than the research on educational mismatches. This is partly due to the fact that educational and skill mismatches are not the same, due to heterogeneity in skills within educational levels and the sorting of the least skilled graduates from each level to less complex jobs (Allen and van der Velden, 2001; Green and McIntosh, 2007). However, part of the problem is also the lack of good measures for skill requirements. Three approaches have been developed to proxy for these skill requirements: WS (asking the worker about the required level), RM (taking the average or median skill level in an occupation as the required skill level), and the JRA (taking the use of skills in a job as a proxy for the required skill level).

We discussed the pros and cons of each of these approaches and concluded that each has its own weaknesses, both theoretically and empirically. Elaborating on this point, we discussed the different views one can have on skill use. On the one hand, one can view the use of skills as a proxy for skill requirement, as in the JRA, or one can consider the use of skill as complementary to skill proficiency. This latter approach is closer to the view of the use of skills in the engagement literature, where using skills is an essential component of the literacy and numeracy constructs (OECD, 2012a). The link between skill proficiency and skill use is also firmly rooted in use-it-or-lose-it theories (Salthouse, 2006) and selfefficacy theory (Bandura, 1977).

In this paper, we developed this idea further by explicitly linking skill use and skill proficiency into a new concept, skill effort. Skill effort is defined as a multiplicative function of skill proficiency and skill use and has an intuitively appealing notion. A worker's skill proficiency can have no productivity effect if the worker's skills are not being used and, vice versa, the productive use of skills is moderated by the worker's skill proficiency level. The idea of using a multiplicative function to combine skill proficiency and skill use has its parallel in the performance literature on ability and motivation (Vroom, 1964), where performance is viewed as the result of a multiplicative function of ability and motivation. 
Our results showed that the new model developed is indeed much better than the original models of skill proficiency and skill use as separate predictors of wages. In a joint model, the multiplicative term supersedes the effect of all the separate terms, a strong indication of the basic notion of our skill effort model, namely, that there can be no productivity effect of skill proficiency when the skills are not being used and vice versa.

We next developed a skill effort matching model similar to the ORU model (Duncan and Hoffman, 1981) for educational mismatches. The model distinguishes three components, one for the returns to required skill effort, one for the returns to overperformance in skill effort, and one for the returns to underperformance. The results show that one standard deviation increase in required skill effort is associated with a wage premium of about $14 \%$. Investing more skill effort in a job than typically required also yields a premium, but not as big, at $6.5 \%$, and investing less skill effort in a job than is typically required yields a wage penalty of $7.3 \%$.

As indicated earlier, we have to be cautious when interpreting these results. These effects are all estimated without including the skill effort match variables of other domains. In an additional analysis, we showed that the above-mentioned effects all decrease by about $10-25 \%$ if we include the skill effort match variables of literacy. This means that the effect sizes mentioned above should be regarded as an upper bound of the effect of numeracy skill effort and the skill effort mismatch variables. On the other hand, the estimates of the required skill effort can also be seen as a lower bound, since the results from the SAE models show that using a more refined classification of occupations (e.g., three-digit ISCO level instead of two-digit ISCO level) yields far higher estimates for the required skill effort. These estimates are about $15 \%$ higher and, again, could be higher still if one uses an even more refined classification. We return to this issue below but, for the moment, we conclude that the estimates for required skill effort will probably not be that different if we include other domains as well as a more refined classification.

The results can best be explained with matching theory. The premium for required skill effort is larger than the premium for expending more skill effort than is typically required on the job, which is in line with typical findings from the educational mismatch literature. When we look at the wage penalties for expending less skill effort than is typically required, we find that this penalty is about as high in absolute terms as the premium for expending more skill effort. In the education mismatch research, the effect of undereducation is usually found to be lower. This result can be explained by the fact that this effect of undereducation is probably underestimated due to selection effects: People who end up in a job for which they are formally undereducated probably have other skills (through experience) that compensate for this lack of required schooling. This is less the case when we look at skill effort, as we do here. 
We conducted additional analyses, looking at differences between age groups. The results indicate that, consistent with the results of Altonji and Pierret (2001), the model works best for prime age and older workers. For younger workers, the effects of the skill effort match variables are considerably weaker. Interestingly, we see that older workers obtain an even higher premium for required skill effort than prime age workers do.

We also included the coverage rate of a country in the model and an interaction of this variable with the skill effort match variables. We found the skill effort match variables to have the strongest effects in countries with a low percentage of workers falling under a collective wage agreement, which is consistent with theories about labor market institutions (Marsden, 1999). This result is broadly in line with those of an alternative model in which we looked at the effect of working in the public sector and the interaction with the skill effort match variables. We showed that there is a wage penalty for working in the public sector but it is highest for workers in occupations with high skill effort requirements.

Finally, we compared the skill effort matching model to other models looking at skill mismatches in the labor market, namely, those of Allen et al. (2013) and Pellizari and Fichen (2013) and a simple educational mismatch (ORU) model. The results show that the skill effort matching model is far superior to the alternative models that assess the effects of skill mismatches (Allen et al., 2013; Pellizari and Fichen, 2013) in terms of explained variances ( $29 \%$ for the skill effort matching model versus $23 \%$ for the other two models) and almost as good as a standard ORU model (31\%). This finding is again strong support for the developed skill effort model. The predictive validity when we look at wage differences is far better than that of any alternative skill matching model. Since schooling variables reflect more skills than just numeracy or literacy, we had expected the ORU model to be better. The fact that the explained variance of our skill effort matching model is very close to that of this ORU model is therefore very encouraging.

These results do not mean that this approach needs no further development. Although the basic idea of skill effort is empirically and theoretically sound, there is an inherent weak point when we turn this into a matching model. Our skill effort matching model is based on an RM approach, with the two problems associated with that approach. The first problem is that of heterogeneity within occupational groups. Our RM approach uses the average skill proficiency or skill use level in an occupation as an indicator of the required skill effort in that occupation. If occupational groups are very heterogeneous, this could lead to the erroneous assignment of workers as being matched or mismatched. We used SAE models to estimate the effect of the heterogeneity. The results show that using the one-digit ISCO occupation classification as Pellizari and Fichen (2013) is likely to result in strong underestimation of the effects of required skill effort. Even using the two-digit ISCO classification, as in this paper, results in an underestimation of the effects of required skill effort, as the SAE models based on the three-digit classification show. Because of data limitations in the LFS, we cannot check whether this also holds for using the three-digit ISCO level, but it 
is likely that a more refined classification, such as the four-digit ISCO level, will reduce the problem of within-occupation heterogeneity even further.

The second problem with using the RM approach is that of defining a good match. Basically, RM models take the average or median levels as indicating a match but, of course, this need not be the case. For example, the fact that $80 \%$ of workers in an occupation have a skill proficiency level that is not higher or lower than a half standard deviation difference from the mean does not automatically imply that all these workers are well matched. In fact, most workers in that occupation could have a skill proficiency level that is too high or too low for that occupation. There is no simple way to address this problem, since we lack direct information on skill requirements from employers. One way to solve this would be to obtain expert opinions on the required skill level in each three-digit ISCO occupation category. Basically, this would be equivalent to what has been called the job analyst method of identifying educational mismatches (Hartog, 2000). This job analyst method is generally regarded as potentially the most reliable way to identify educational mismatches (Verhaest and Omey, 2006). The experts would need to express these required skill levels in the same scale metric as the possessed skills are measured in to directly compare the two. We advise the OECD to adopt an initiative to consult national job experts and international domain-specific experts (e.g., in numeracy, literacy, and problem solving), to provide estimates of the required skill levels for each three-digit ISCO occupation category for the countries currently participating in the PIAAC survey and its follow-ups.

\section{References}

Allen, J. and Bijlsma, I. (2015), Skill Profiles of Occupations: Robust Multi-level Estimates Based on PIAAC Data, Maastricht: ROA

Allen, J. and Van der Velden, R. (2001), Educational Mismatches Versus Skill Mismatches: Effects on Wages, Job-Related Training, and On-the-Job Search, Oxford Economic Papers, 3: 434-452.

Allen, J. and Van der Velden, R. (2005), The Role of Self-Assessment in Measuring Skills, REFLEX Working paper 2, Maastricht: ROA.

Allen, J. and Van der Velden, R. (eds.) (2011), The Flexible Professional in the Knowledge Society: New Challenges for Higher Education, Higher Education Dynamics, 35, Dordrecht: Springer

Allen, J., Levels, M., and Van der Velden, R. (2013), Skill mismatch and skill use in developed countries: Evidence from the PIAAC study, ROA-RM-2013/17, Maastricht

Altonji, J. and Pierret, C. (2001), Employer Learning and Statistical Discrimination, The Quarterly Journal of Economics, 116 (1): 313-350.

Arrow, K.J. (1973), Higher education as a filter, Journal of Public Economics, 2 (3): 193-216.

Bandura, A. (1977), Self-efficacy: Toward a unifying theory of behavioral change, Psychological Review, 84 (2): 191-215 
Battu, H., Belfield, C. and Sloane, P. (2000), How well can we measure graduate overeducation and its effects? National Institute Economic Review, 171 (1): 82-93.

Becker, G. (1964), Human Capital. A Theoretical and Empirical Analysis, with Special Reference to Education. New York: NBER.

Bijlsma, I., Van den Brakel, J., Van der Velden, R. and Allen, J. (2017), Estimating literacy levels at a detailed regional level: an application using Dutch data, Maastricht: ROA.

Bills, D. (2003), Credentials, Signals and Screens: Explaining the Relationship between Schooling and Job Assignment, Review of Educational Research, 73: 441-70.

Bynner, J., and Parsons, S. (1998), Use It or Lose It? The Impact of Time out of Work on Literacy and Numeracy Skills, London: Basic Skills Agency.

Collins, R. (1979), The Credential Society: An Historical Sociology of Education and Stratification, New York: Academic Press.

Desjardins, R. and Warnke, A. (2012), Ageing and Skills: A Review and Analysis of Skill Gain and Skill Loss Over the Lifespan and Over Time, OECD Education Working Papers, No. 72, Paris: OECD Publishing.

Duncan, G. and Hoffman, S. (1981) The incidence and wage effects of overeducation, Economics of Education Review, 1: 75-86.

Freeman, R. (1976), The Overeducated American, New York: Academic Press.

Gangl, M. (2001), European patterns of labour market entry. A dichotomy of occupationalized vs. nonoccupationalized systems? European Societies, 3 (4): 471-494.

Green, F. and McIntosh, S. (2007) Is there a genuine under-utilization of skills amongst the overqualified? Applied Economics, 39: 427-39.

Green, F., Felstead, A. and Gallie, D. (2013), Skills and Work Organisation in Britain, In: F. Green and M. Keese (eds), Job Tasks, Work Skills and the Labour Market, Paris: OECD Publishing.

Groot, W. and Maassen van den Brink, H. (2000), Overeducation in the labor market: A meta-analysis, Economics of Education Review, 19 (2): 149-158.

Guthrie, J. and Wigfield, A. (2000), Engagement and motivation in reading. In: M. Kamil, P. Mosenthal, P. Pearson, and R. Barr (Eds.), Handbook of reading research (3rd. ed.), New York: Longman, 403-422.

Halaby, C. (1994) Overeducation and skill mismatch, Sociology of Education, 67 (1): 47-59.

Hanushek, E. and Woessmann, L. (2011) The economics of international differences in educational achievement, In: E. Hanushek, S. Machin, and L. Woessmann (eds), Handbook of the Economics of Education, vol. 3, North-Holland, Amsterdam, 89-200.

Hanushek, E., Schwerdt, G., Wiederhold, S., and Woessmann, L. (2015), Returns to skills around the world: evidence from PIAAC, European Economic Review, 73: 103-130

Hartog, J. (2000) Overeducation and earnings: where are we, where should we go? Economics of Education Review, 19: 131-47. 
King, G, Murray, C, Salomon, J. and Tandon, A. (2004), Enhancing the Validity and Cross-Cultural Comparability of Measurement in Survey Research, American Political Science Review, 98 (1): 191207.

King, G and Wand, J. (2004), Comparing Incomparable Survey Responses: New Tools for Anchoring Vignettes, Mimeo, Cambridge MA: Harvard University

Krahn, H., and Lowe, G. (1998), Literacy Utilization in Canadian Workplaces. Ottawa and Hull: Statistics Canada and Human Resource Development Canada.

Levels, M. and Van der Velden, R. (fortcoming), Use-it-or-lose-it? Explaining age-related differences in key information processing skills. In: I. Kirsch, E. Gonzalez, M. von Davier and K. Yamamoto (eds.), The Importance of Skills and How to Assess Them, Cham: Springer international Publishing AG.

Levels, M., Van der Velden, R. and Allen, J. (2014), Educational mismatches and skills: new empirical tests of old hypotheses, Oxford Economic Papers, 66 (4): 959-982.

Marsden, D. (1999), A Theory of Employment Systems: Micro Foundations for Societal Diversity, Oxford: Oxford University Press.

McGuiness, S. (2006), Overeducation in the labor market, Journal of Economic Surveys, 20 (3): 387-418.

Mincer, J. (1974), Schooling, Experience, and Earnings, New York: NBER Press.

Mincer, J. and Ofek, H. (1982), Interrupted Work Careers: Depreciation and Restoration of Human Capital, Journal of Human Resources, 17: 3-24.

Multon, K., Brown, S. and Lent, R. (1991), Relation of self-efficacy beliefs to academic outcomes: A metaanalytic investigation, Journal of Counseling Psychology, 18: 30-38.

OECD (2012a), Literacy, Numeracy and Problem Solving in Technology-Rich Environments: Framework for the OECD Survey of Adult Skills, Paris: OECD Publishing.

OECD (2012b), Trade union density and collective bargaining coverage, 1990 and latest year, In: OECD Employment Outlook 2012, Paris: OECD Publishing.

OECD (2012c), Employment Protection Legislation Index. Paris: OECD Publishing.

OECD (2013a), Skills Outlook: first results from the OECD Survey of Adult Skills (Volume 1), Paris: OECD Publishing.

OECD (2013b), Technical Report of the OECD Survey of Adult Skills (PIAAC), Paris: OECD Publishing.

Pellizari, M. and Fichen, A. (2013), A New Measure of Skills Mismatch, Theory and Evidence from the Survey of Adult Skills (PIAAC), OECD Social, Employment and Migration Working Papers, No. 153, Paris: OECD Publishing

Perry, A. Wiederhold, S. and Ackermann-Piek, D. (2014), How Can Skill Mismatch be Measured? New Approaches with PIAAC, Methods, data, analyses, 8 (2): 137-174

Pfeiffer, F. and Reuss, K. (2008), Age-dependent skill formation and returns to education, Labour Economics, 15 (4): 631-646.

Quintini, G. (2011), Over-qualified or under-skilled: A review of existing literature, OECD Social, Employment and Migration Working Papers 121. Paris: OECD Publishing. 
Salthouse, T. (2006), Mental exercise and mental ageing: Evaluating the validity of the "use it or lose it" hypothesis, Perspectives on Psychological Science, 1 (1): 68-87.

Sattinger, M. (1993), Assignment Models of the Distribution of Earnings, Journal of Economic Literature, 31, 851-880.

Sattinger, M. (2012), Qualitative mismatches, Foundations and Trends, Microeconomics, 8, 1-168.

Spence, M. (1973), Job market signaling, Quarterly Journal of Economics, 87 (1): 355-374.

Thurow, L. (1975), Generating Inequality, London: Macmillan.

Van der Velden, R. and Van Smoorenburg, M. (1997), The Measurement of Overeducation and Undereducation: Self-report vs. Job-analyst Method, ROA Research Memorandum 1997/2E, Maastricht: ROA.

Van Iddekinge, C., Aguinis, H., and Mackey, J. (2014), A meta-analysis of the relative and interactive effects of ability and motivation on performance. Paper presented at the meeting of the Academy of Management, Philadelphia, PA.

Verhaest, D. and Omey, E. (2006), Measuring the incidence of over- and undereduction, Quality and Quantity, 40 (5): 416-436.

Vroom, V. H. (1964), Work and Motivation, New York : Wiley. 
Figure 1 Effect on hourly wage of increasing one quartile in numeracy skill or numeracy use

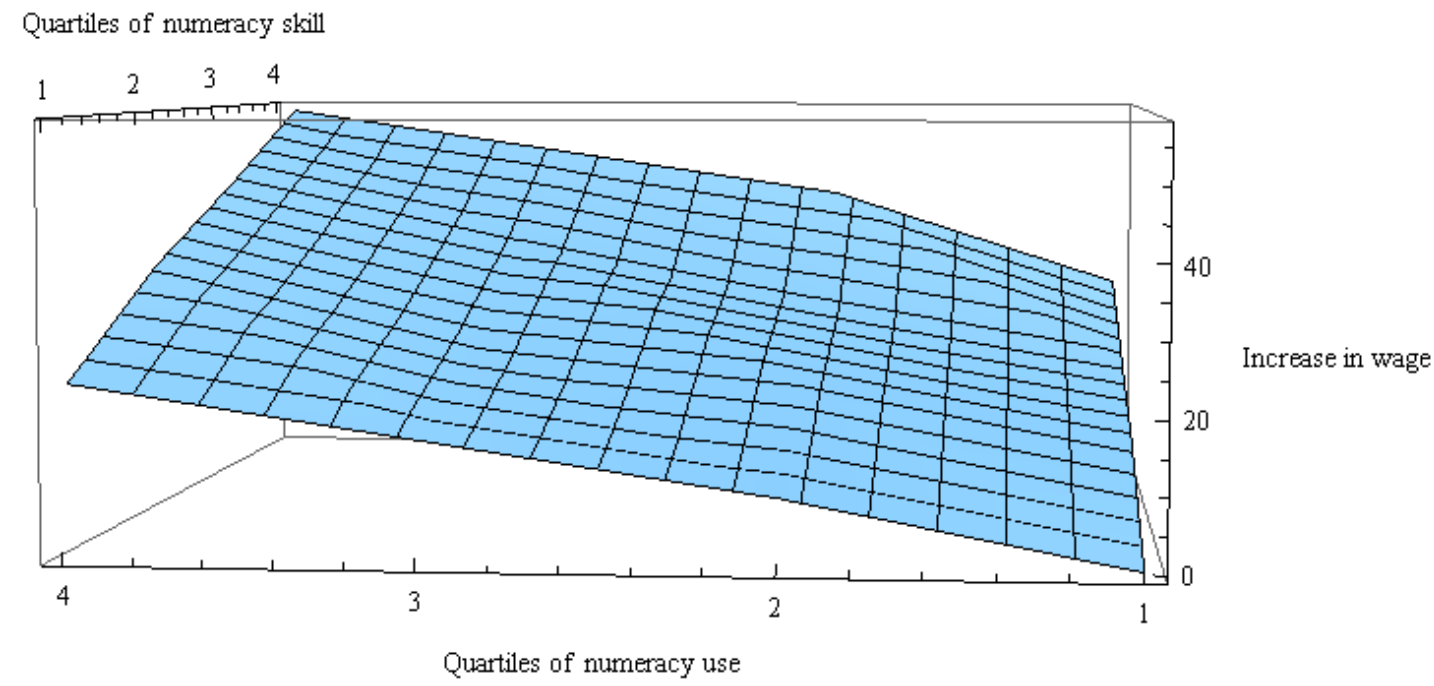

Figure 2 Explained variance skill effort matching models per country plotted against the coverage rate

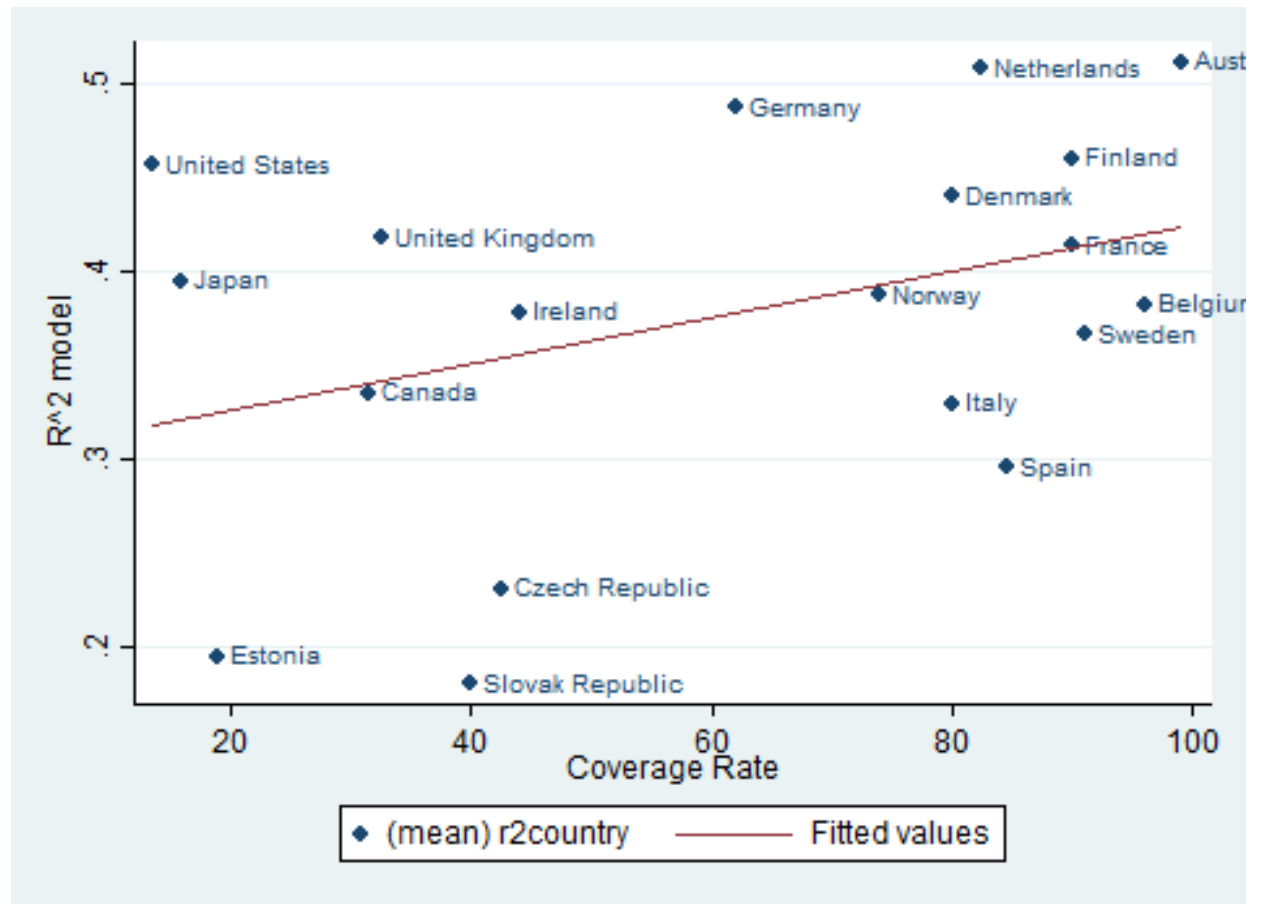


Figure 3 Explained variance log wage and percentile rank wage distribution per country

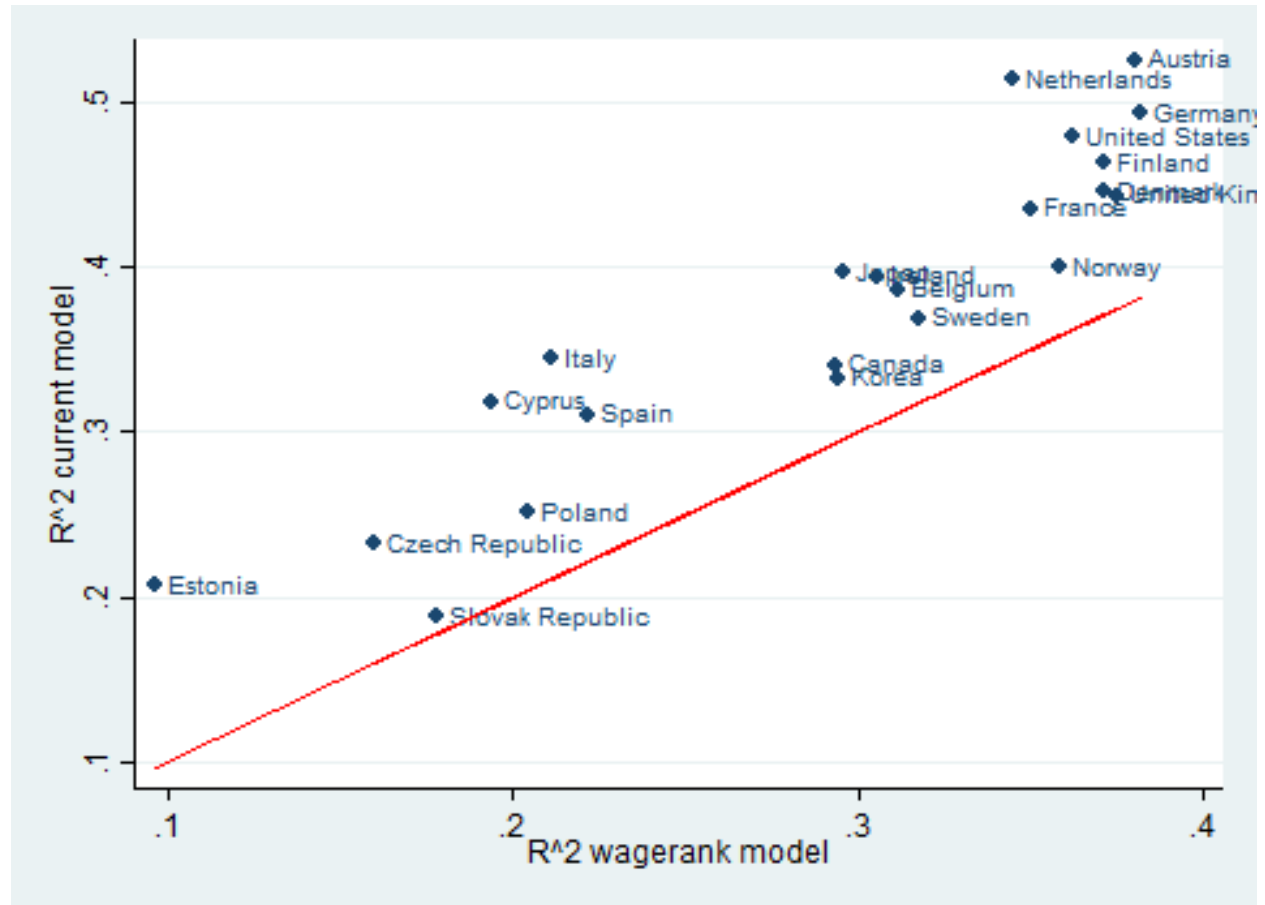

Figure 4 Explained variance skill effort matching model and ORU model per country

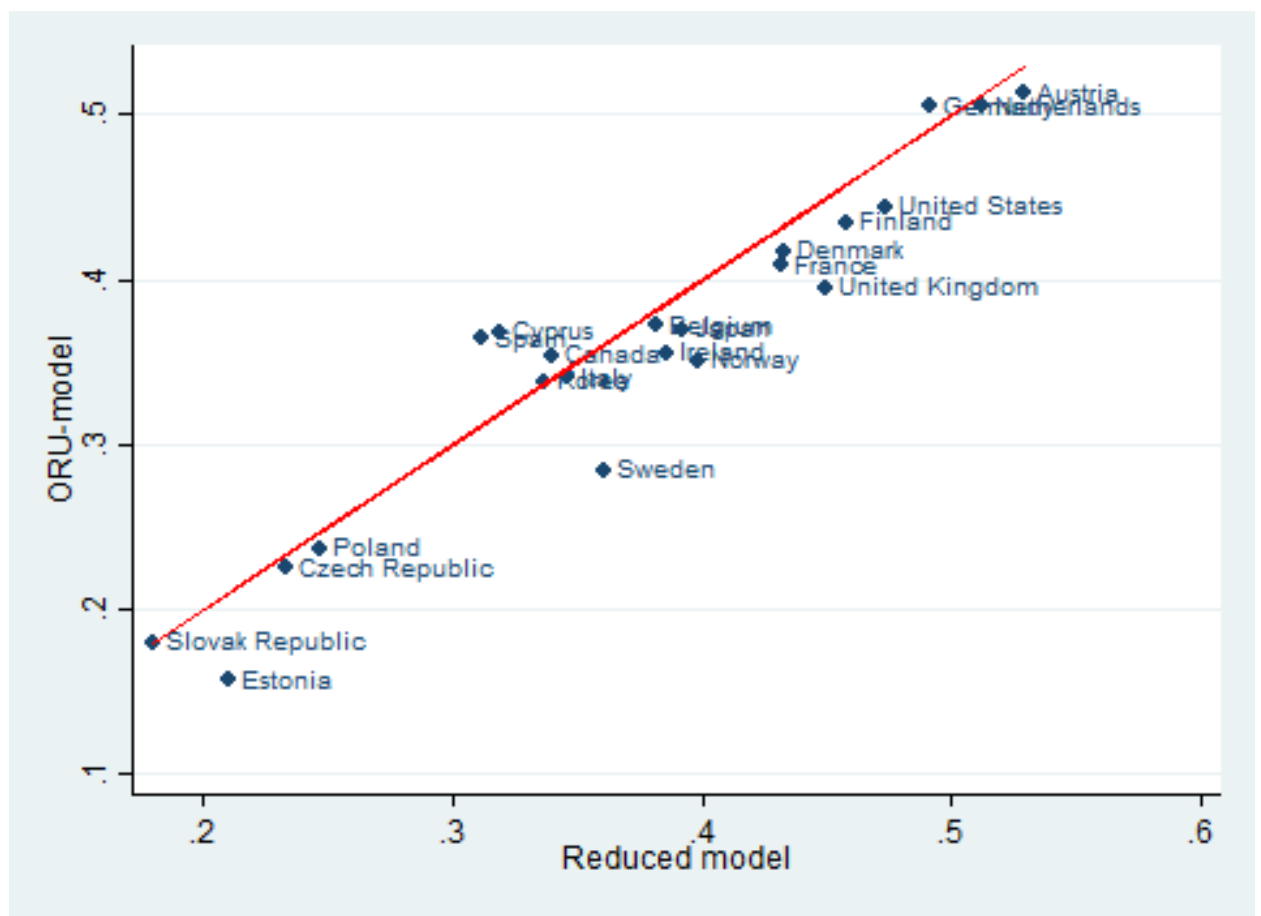


Figure 5 Relation between coverage rate and wage effect of required skill effort

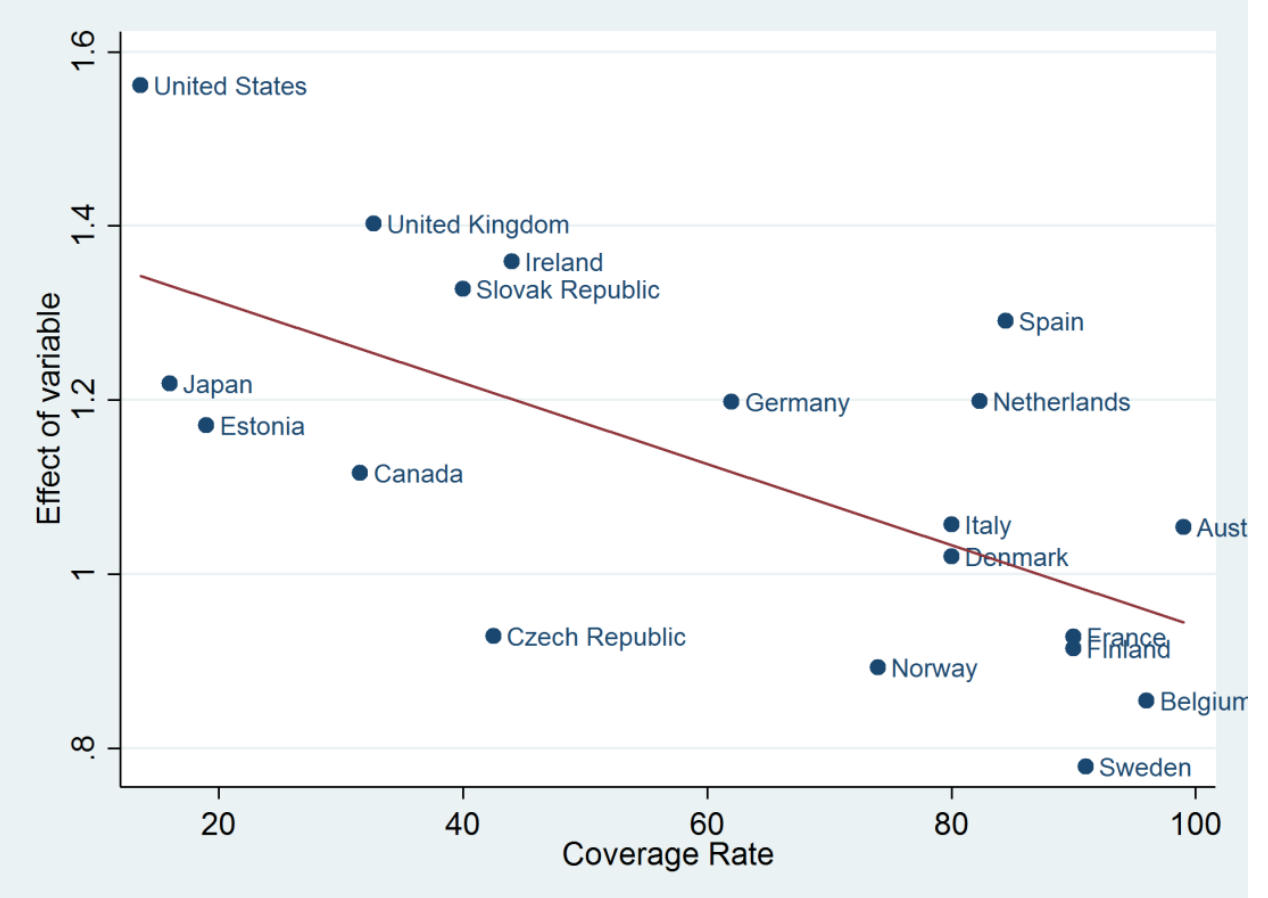


Table 1 Comparing different specifications of the skill effort model

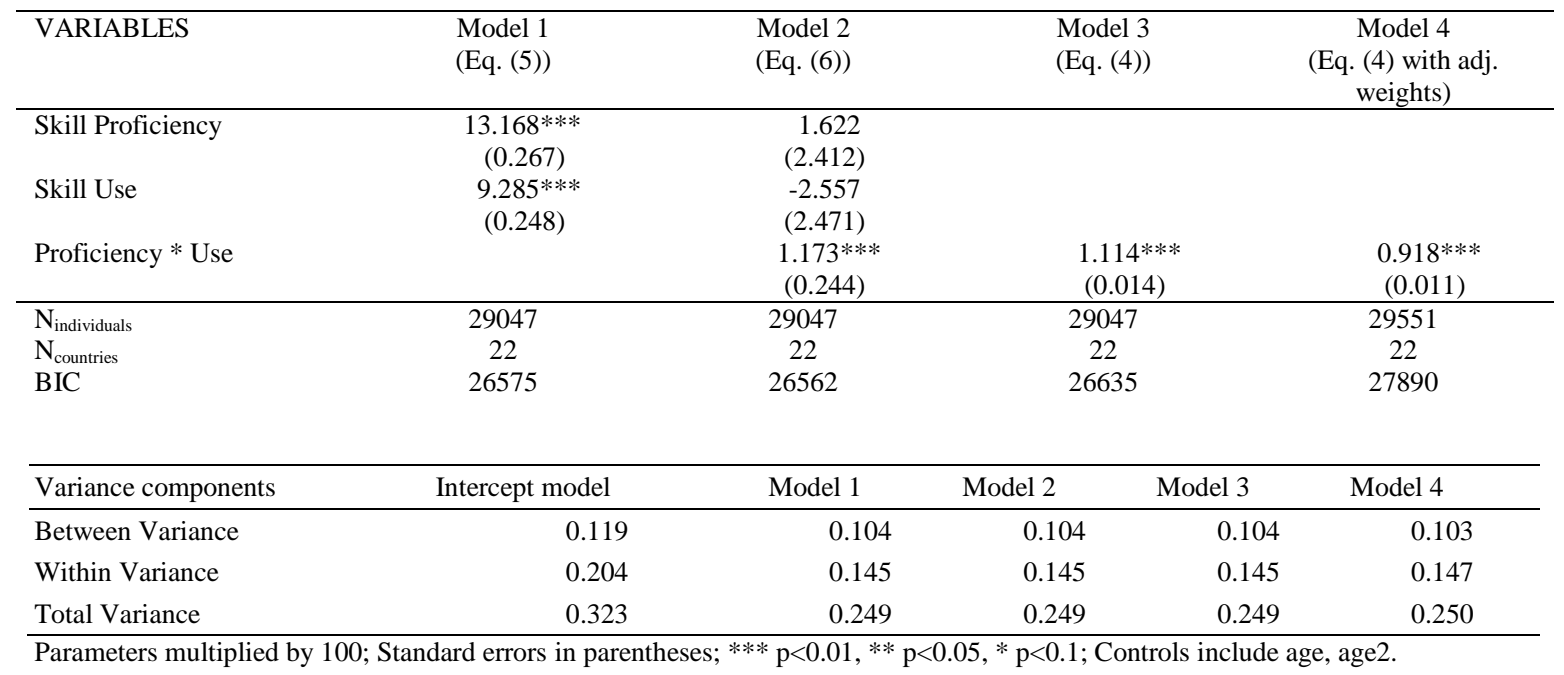


Table 2 Skill effort matching model (eq. (7))

\begin{tabular}{lc}
\hline VARIABLES & \\
\hline Returns to required skill effort & $1.129 * * *$ \\
& $(0.012)$ \\
Returns to overperformance in skill effort & $0.521^{* * *}$ \\
& $(0.022)$ \\
Returns to underperformance in skill effort & $-0.584 * * *$ \\
& $(0.022)$ \\
\hline $\mathrm{N}_{\text {individuals }}$ & 29552 \\
$\mathrm{~N}_{\text {countries }}$ & 22 \\
BIC & 25049
\end{tabular}

\begin{tabular}{lcc}
\hline Variance components & Intercept model & Full Model \\
\hline Between Variance & 0.119 & 0.094 \\
Within Variance & 0.204 & 0.136 \\
Total Variance & 0.323 & 0.230
\end{tabular}

Parameters multiplied by 100; Standard errors in parentheses; ${ }^{* * *} \mathrm{p}<0.01,{ }^{* *} \mathrm{p}<0.05,{ }^{*} \mathrm{p}<0.1$; Controls include age, age2. 
Table 3 Skill effort matching model for different age groups

\begin{tabular}{|c|c|c|c|}
\hline VARIABLES & Young age & Prime age & Old age \\
\hline \multirow[t]{2}{*}{ Returns to required skill effort } & $0.777 * * *$ & $1.248 * * *$ & $1.379 * * *$ \\
\hline & $(0.019)$ & $(0.018)$ & $(0.024)$ \\
\hline \multirow[t]{2}{*}{ Returns to overperformance in skill effort } & $0.371 * * *$ & $0.574 * * *$ & $0.561 * * *$ \\
\hline & $(0.032)$ & $(0.035)$ & $(0.054)$ \\
\hline \multirow[t]{2}{*}{ Returns to underperformance in skill effort } & $-0.429 * * *$ & $-0.715 * * *$ & $-0.681 * * *$ \\
\hline & $(0.037)$ & $(0.034)$ & $(0.041)$ \\
\hline $\mathrm{N}_{\text {individuals }}$ & 11022 & 11320 & 7110 \\
\hline $\mathrm{N}_{\text {countries }}$ & 22 & 22 & 22 \\
\hline BIC & 8865 & 9233 & 6133 \\
\hline
\end{tabular}

Parameters multiplied by 100; Standard errors in parentheses; *** $\mathrm{p}<0.01, * * \mathrm{p}<0.05, * \mathrm{p}<0.1$; Controls include age, age2.

Young Age (16-34)

\begin{tabular}{lcc}
\hline Variance components & Intercept model & Model \\
\hline Between Variance & 0.086 & 0.075 \\
Within Variance & 0.180 & 0.128 \\
Total Variance & 0.266 & 0.203 \\
\hline
\end{tabular}

\section{Prime Age (35-49)}

\begin{tabular}{lcr}
\hline Variance components & Intercept model & Model \\
\hline Between Variance & 0.122 & 0.105 \\
Within Variance & 0.182 & 0.128 \\
Total Variance & 0.304 & 0.233 \\
\hline
\end{tabular}

\section{Old Age (50-65)}

\begin{tabular}{lcr}
\hline Variance components & Intercept model & Model \\
\hline Between Variance & 0.153 & 0.134 \\
Within Variance & 0.201 & 0.135 \\
Total Variance & 0.354 & 0.269 \\
\hline
\end{tabular}


Table 4 Skill effort matching model for literacy and numeracy

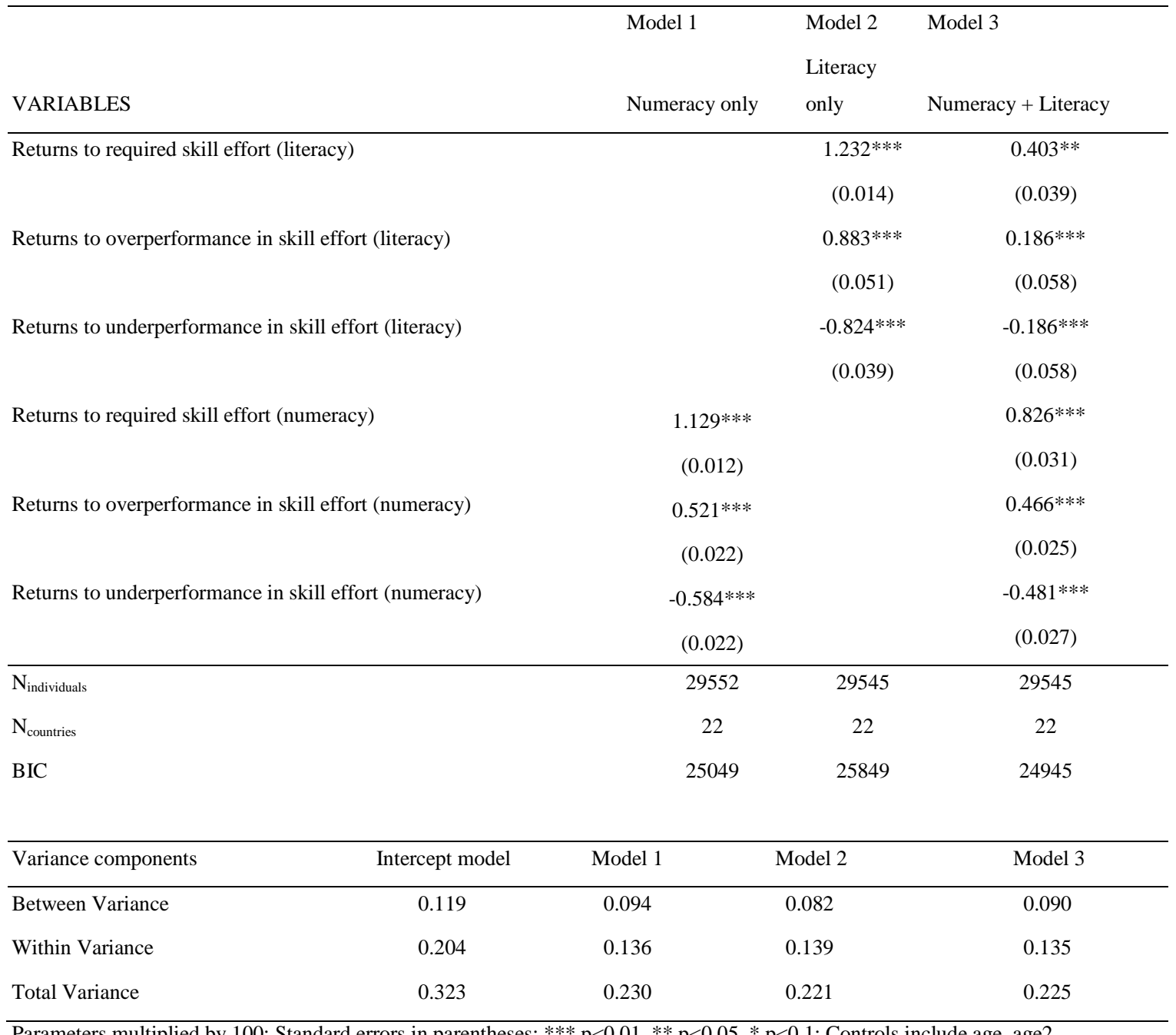

Parameters multiplied by 100; Standard errors in parentheses; *** $\mathrm{p}<0.01, * * \mathrm{p}<0.05, * \mathrm{p}<0.1$; Controls include age, age2. 
Table 5 Skill effort matching model with coverage rate

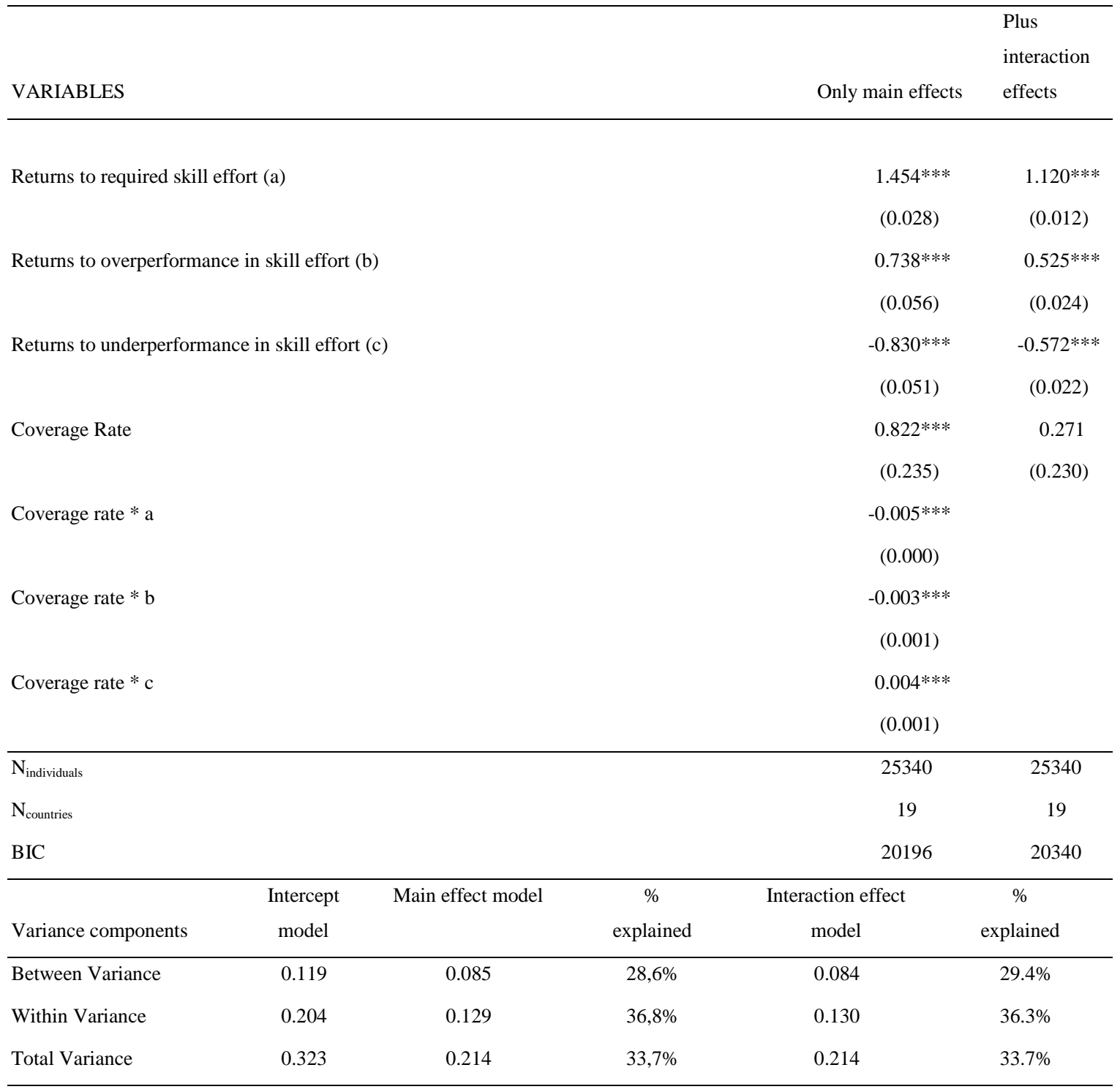

Parameters multiplied by 100; Standard errors in parentheses; *** $\mathrm{p}<0.01, * * \mathrm{p}<0.05, * \mathrm{p}<0.1$; Controls include age, age2. 
Table 6 Skill effort matching model with public sector

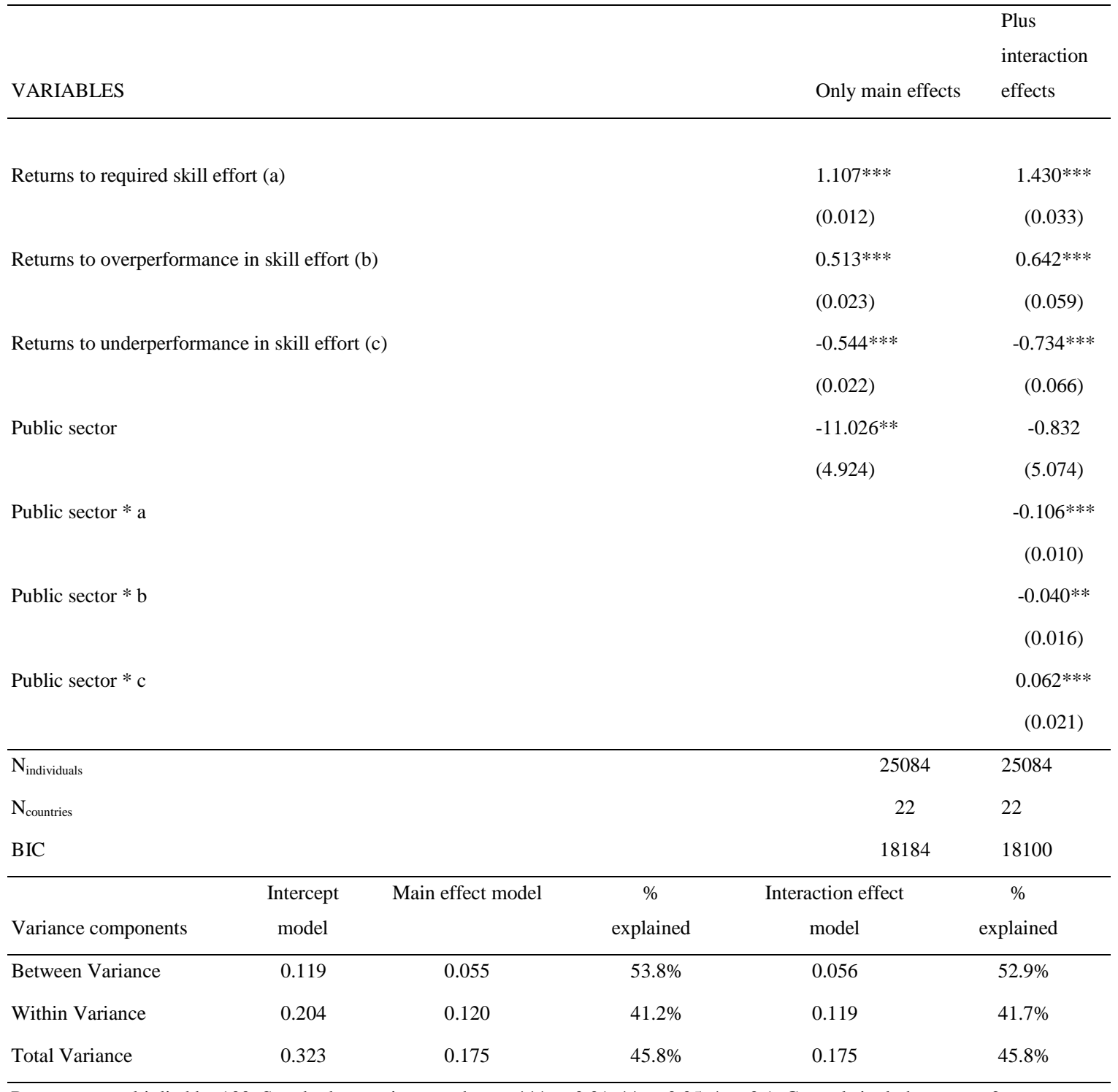

Parameters multiplied by 100; Standard errors in parentheses; *** $\mathrm{p}<0.01, * * \mathrm{p}<0.05, * \mathrm{p}<0.1$; Controls include age, age2. 
Table 7 Skill effort matching model compared with alternative models

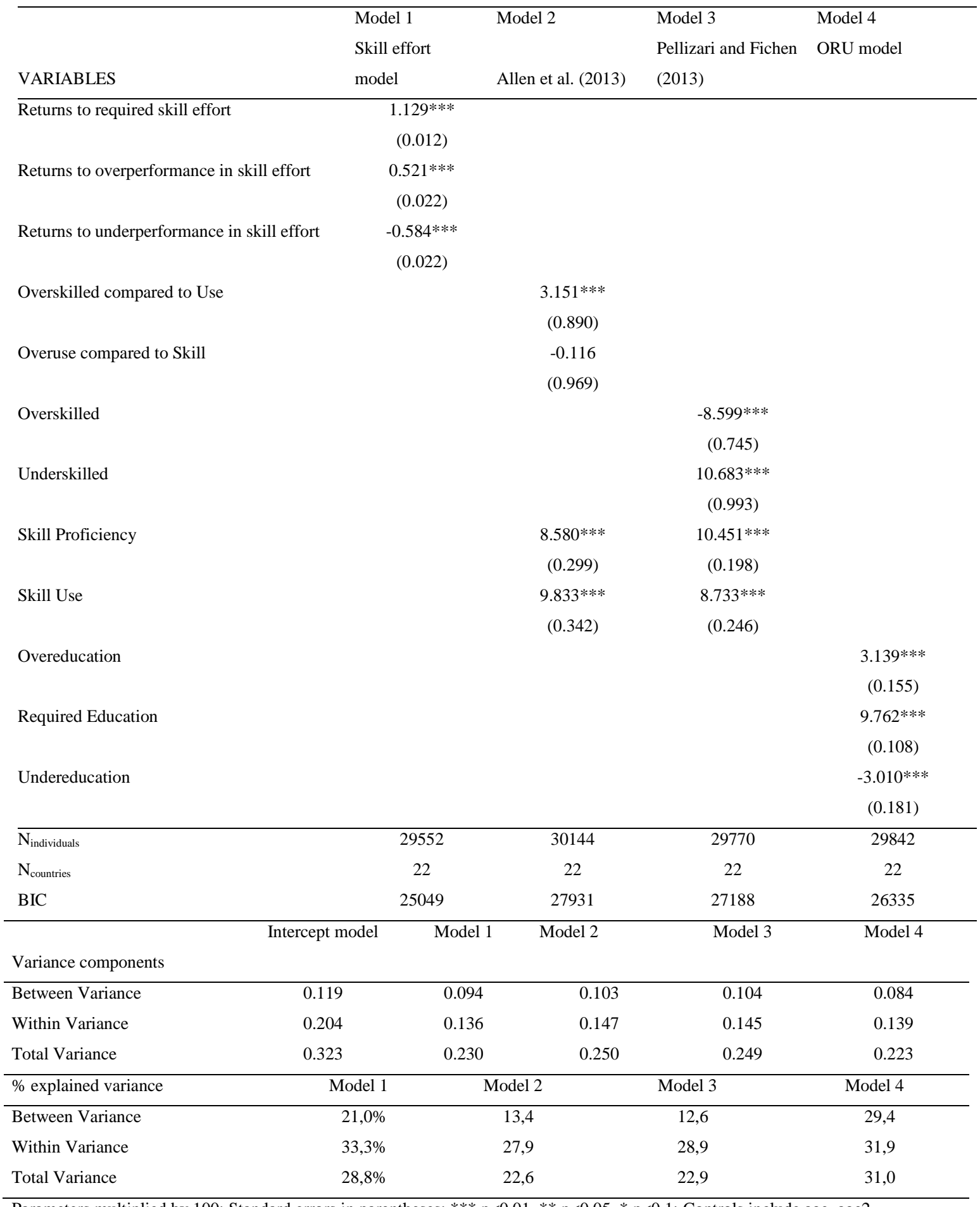

Parameters multiplied by 100; Standard errors in parentheses; *** $\mathrm{p}<0.01,{ }^{* *} \mathrm{p}<0.05,{ }^{*} \mathrm{p}<0.1$; Controls include age, age2. 
Table 8 Skill effort matching model for one-, two-, and three-digit ISCO levels (results for The Netherlands only)

\begin{tabular}{|c|c|c|c|}
\hline VARIABLES & One-digit ISCO & Two-digit ISCO & Three-digit ISCO \\
\hline \multirow[t]{2}{*}{ Returns to required skill effort } & $1.393 * * *$ & $1.943 * * *$ & $2.237 * * *$ \\
\hline & $(0.054)$ & $(0.076)$ & $(0.102)$ \\
\hline \multirow[t]{2}{*}{ Returns to overperformance in skill effort } & $0.897 * * *$ & $0.831 * * *$ & $0.777 * * *$ \\
\hline & $(0.119)$ & $(0.149)$ & $(0.121)$ \\
\hline \multirow[t]{2}{*}{ Returns to underperformance in skill effort } & $-1.249 * * *$ & $-1.292 * * *$ & $-1.283 * * *$ \\
\hline & $(0.149)$ & $(0.163)$ & $(0.130)$ \\
\hline $\mathrm{N}_{\text {individuals }}$ & 1286 & 1279 & 1315 \\
\hline R-square & 0.506 & 0.504 & 0.511 \\
\hline
\end{tabular}

Parameters multiplied by 100; Standard errors in parentheses; *** $\mathrm{p}<0.01,{ }^{* *} \mathrm{p}<0.05,{ }^{*} \mathrm{p}<0.1$; Controls include age, age2. 


\section{Appendix A: Calculation of robust country-specific estimates at the two-digit ISCO level of skill proficiency and skill use}

A problem with the PIAAC data set is that it has only a limited number of observations available for each two-digit ISCO occupation category in a country. To avoid inaccuracies in the assessment of the average skill proficiency and skill use levels for these occupations, Allen and Bijlsma (2013) developed a crossclassified multilevel model in which individuals are nested in both international two-digit ISCO occupation categories as well as in national one-digit ISCO occupation categories. The national averages for each twodigit ISCO occupation category are thus a function of both the national data for the individual's one-digit ISCO occupation category as well as the international data of the individual's two-digit ISCO occupation category. To illustrate, the average numeracy level of Dutch building trade workers (ISCO 71) is estimated as a weighted average of the numeracy level of all Dutch craft workers (ISCO 7), the numeracy levels of building trade workers in other countries, as well as the directly observed numeracy level of Dutch building trade workers in the data. To avoid the problem where certain countries can have very different skill profiles and would thus give rise to a systematic bias, the contribution of other countries is weighted such that countries that are more similar to the reference country (the Netherlands in this case) also have higher weights. These weights are based on the between-country correlation between the preliminary two-digit occupational skill estimates of the reference country and all the other countries in the data. This correlation is squared and can thus be conceived of as the amount of variance in the reference country's occupational skill structure that can be explained by the occupational skill structures of the other countries. By definition, the respondents in the reference country are assigned a weight of one and those in the other countries are assigned a weight between zero and one (usually around 0.7 ). The estimates were carried out for all two-digit occupation categories, with the exception of army occupations (ISCO 0). We use this method to obtain the country-specific estimates of the skill proficiency and skill use levels in each two-digit ISCO occupation category. An Excel spreadsheet with these estimates is available upon request. 


\section{Appendix B}

Table B1 Robustness check using literacy instead of numeracy

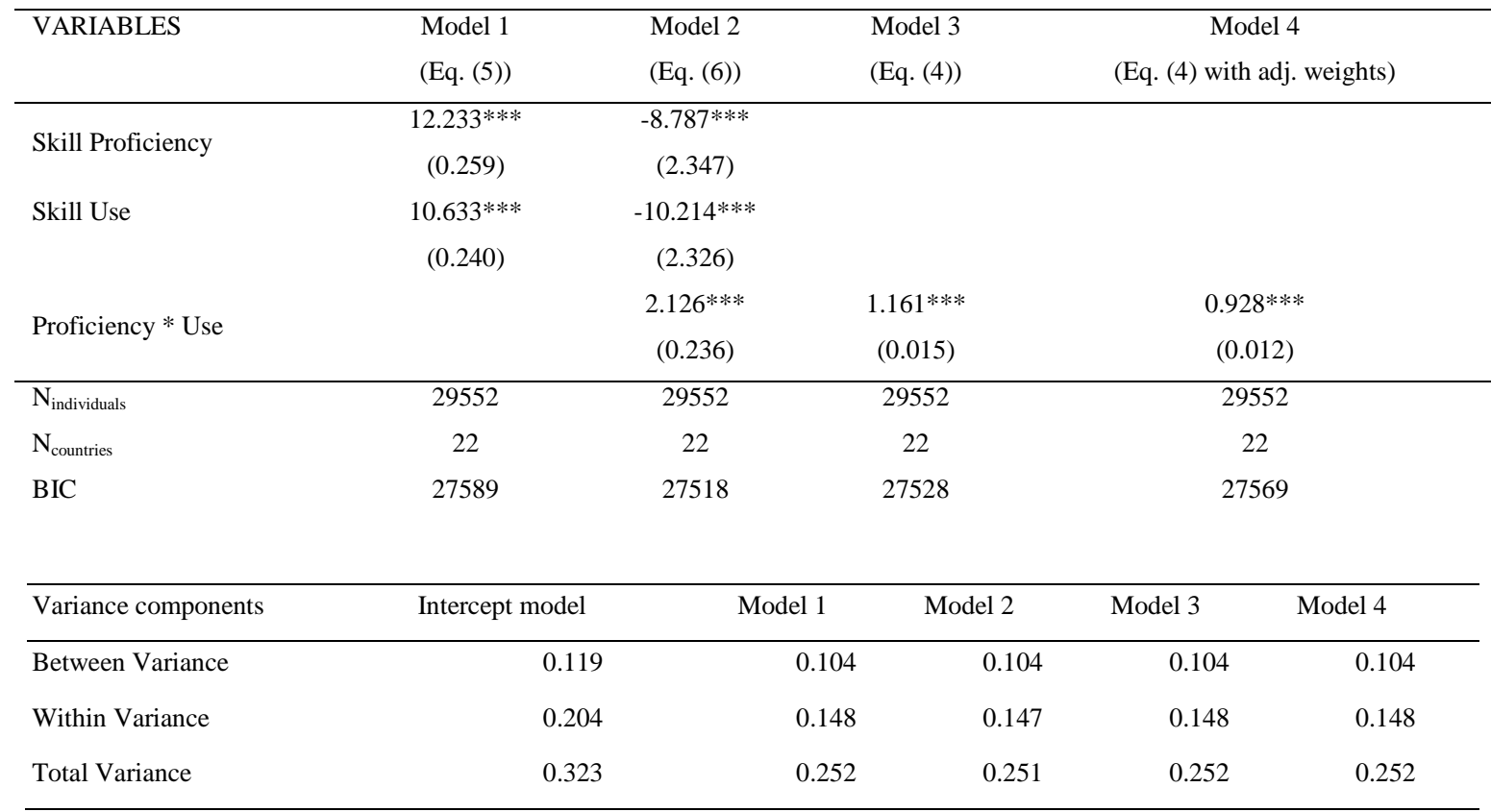

Parameters multiplied by 100; Standard errors in parentheses; *** $\mathrm{p}<0.01, * * \mathrm{p}<0.05,{ }^{*} \mathrm{p}<0.1$; Controls include age, age 2 . 
Table B2 Skill effort matching model (eq. (8)) using separate PV's

\begin{tabular}{|c|c|c|c|c|c|}
\hline VARIABLES & $\begin{array}{c}\text { PV1 } \\
\text { Full Model }\end{array}$ & $\begin{array}{c}\text { PV2 } \\
\text { Full model }\end{array}$ & $\begin{array}{c}\text { PV } 4 \\
\text { Full model }\end{array}$ & $\begin{array}{c}\text { PV } 9 \\
\text { Full model }\end{array}$ & $\begin{array}{c}\text { PV10 } \\
\text { Full Model }\end{array}$ \\
\hline Returns to required skill effort & $\begin{array}{l}1.103 * * * \\
(0.012)\end{array}$ & $\begin{array}{l}1.101 * * * \\
(0.012)\end{array}$ & $\begin{array}{l}1.102 * * * \\
(0.012)\end{array}$ & $\begin{array}{l}1.105 * * * \\
(0.012)\end{array}$ & $\begin{array}{l}1.107 * * * \\
(0.012)\end{array}$ \\
\hline $\begin{array}{l}\text { Returns to overperformance in s } \\
\text { effort }\end{array}$ & $\begin{array}{c}0.466^{* * * *} \\
(0.021)\end{array}$ & $\begin{array}{c}0.465 * * * \\
(0.021)\end{array}$ & $\begin{array}{c}0.467 * * * \\
(0.021)\end{array}$ & $\begin{array}{c}0.488^{* * *} \\
(0.022)\end{array}$ & $\begin{array}{c}0.456 * * * \\
(0.021)\end{array}$ \\
\hline $\begin{array}{l}\text { Returns to underperformance in } \\
\text { skill effort }\end{array}$ & $\begin{array}{c}-0.528^{* * *} \\
(0.021)\end{array}$ & $\begin{array}{c}-0.517 * * * \\
(0.021)\end{array}$ & $\begin{array}{c}-0.522 * * * \\
(0.021)\end{array}$ & $\begin{array}{c}-0.530 * * * \\
(0.021)\end{array}$ & $\begin{array}{c}-0.547 * * * \\
(0.021)\end{array}$ \\
\hline $\begin{array}{l}N_{\text {individuals }} \\
N_{\text {countries }}\end{array}$ & $\begin{array}{c}29552 \\
22\end{array}$ & $\begin{array}{c}29552 \\
22\end{array}$ & $\begin{array}{c}29552 \\
22\end{array}$ & $\begin{array}{c}29552 \\
22\end{array}$ & $\begin{array}{c}29552 \\
22\end{array}$ \\
\hline
\end{tabular}

Parameters multiplied by 100; Standard errors in parentheses; *** $\mathrm{p}<0.01, * * \mathrm{p}<0.05, * \mathrm{p}<0.1$; Controls include age, age2. 
Table B3 Robustness check comparing the skill effort matching model using different cut-off points

\begin{tabular}{|c|c|c|c|}
\hline & & Model 1 & Model 2 \\
\hline VARIABLES & & St.dev. $=0.5$ & St.dev. $=1.0$ \\
\hline Returns to required sk & & $1.129 * * *$ & $1.128 * * *$ \\
\hline & & $(0.012)$ & $(0.012)$ \\
\hline Returns to overperforn & & $0.521 * * *$ & $0.531 * * *$ \\
\hline & & $(0.022)$ & $(0.022)$ \\
\hline Returns to underperfor & & $-0.584 * * *$ & $-0.593 * * *$ \\
\hline & & $(0.022)$ & $(0.022)$ \\
\hline$\overline{N_{\text {individuals }}}$ & & 29552 & 29546 \\
\hline$N_{\text {countries }}$ & & 22 & 22 \\
\hline BIC & & 25049 & 26312 \\
\hline Variance components & Intercept model & Model 1 & Model 2 \\
\hline Between Variance & 0.152 & 0.093 & 0.094 \\
\hline Within Variance & 0.202 & 0.136 & 0.136 \\
\hline Total Variance & 0.354 & 0.229 & 0.228 \\
\hline
\end{tabular}

Parameters multiplied by 100; Standard errors in parentheses; *** $\mathrm{p}<0.01, * * \mathrm{p}<0.05, * \mathrm{p}<0.1$; Controls include age, age2. 
Table B4 Robustness check comparing the skill effort matching model using log wages or percentile rank in the wage distribution

\begin{tabular}{|c|c|c|c|c|}
\hline & & & Model 1 & Model 2 \\
\hline \multicolumn{3}{|l|}{ VARIABLES } & Log wage & Percentile rank \\
\hline \multirow{2}{*}{\multicolumn{3}{|c|}{ Returns to required skill effort }} & $1.129 * * *$ & $0.663 * * *$ \\
\hline & & & $(0.012)$ & $(0.008)$ \\
\hline \multirow{2}{*}{\multicolumn{3}{|c|}{ Returns to overperformance in skill effort }} & $0.521 * * *$ & $0.282 * * *$ \\
\hline & & & $(0.022)$ & $(0.014)$ \\
\hline \multirow{2}{*}{\multicolumn{3}{|c|}{ Returns to underperformance in skill effort }} & $-0.584 * * *$ & $-0.286^{* * *}$ \\
\hline & & & $(0.022)$ & $(0.014)$ \\
\hline \multicolumn{3}{|l|}{$\mathrm{N}_{\text {individuals }}$} & 29552 & 29552 \\
\hline \multicolumn{3}{|l|}{$\mathrm{N}_{\text {countries }}$} & 22 & 22 \\
\hline \multicolumn{3}{|l|}{ BIC } & 25049 & 1344 \\
\hline Variance components & Intercept model & Model 1 & Intercept & Model 2 \\
\hline Between Variance & 0.119 & 0.093 & 0.000 & 0.002 \\
\hline Within Variance & 0.204 & 0.136 & 0.083 & 0.061 \\
\hline Total Variance & 0.323 & 0.229 & 0.083 & 0.063 \\
\hline
\end{tabular}

Parameters multiplied by 100; Standard errors in parentheses; $* * * \mathrm{p}<0.01, * * \mathrm{p}<0.05, * \mathrm{p}<0.1 ;$ Controls include age, age2. 
Table B5 Skill effort matching model with EPL

\begin{tabular}{|c|c|c|c|c|}
\hline VARIABLES & & & & EPL \\
\hline Returns to required ski & it (a) & & & $1.465 * * *$ \\
\hline & & & & $(0.037)$ \\
\hline Returns to overperforn & in skill effort & & & $0.711 * * *$ \\
\hline & & & & $(0.071)$ \\
\hline Returns to underperfor & in skill effor & & & $-0.866 * * *$ \\
\hline & & & & $(0.071)$ \\
\hline EPL & & & & 5.324 \\
\hline & & & & $(10.057)$ \\
\hline $\mathrm{EPL} * \mathrm{a}$ & & & & $-0.167 * * *$ \\
\hline & & & & $(0.017)$ \\
\hline $\mathrm{EPL} * \mathrm{~b}$ & & & & $-0.087 * *$ \\
\hline & & & & $(0.034)$ \\
\hline $\mathrm{EPL} * \mathrm{c}$ & & & & $0.142 * * *$ \\
\hline & & & & $(0.034)$ \\
\hline $\mathrm{N}_{\text {individuals }}$ & & & & 28757 \\
\hline $\mathrm{N}_{\text {countries }}$ & & & & 21 \\
\hline BIC & & & & 24363 \\
\hline Variance components & Intercept & EPL model & $\%$ explained & \\
\hline Between Variance & 0.127 & 0.094 & $26.0 \%$ & \\
\hline Within Variance & 0.201 & 0.135 & $32.8 \%$ & \\
\hline Total Variance & 0.328 & 0.229 & $30.2 \%$ & \\
\hline
\end{tabular}

Parameters multiplied by 100 ; Standard errors in parentheses; $* * * \mathrm{p}<0.01, * * \mathrm{p}<0.05, * \mathrm{p}<0.1$; Controls include age, age2. 


\section{Appendix C: Development of the SAE model}

Direct estimates of the PIAAC data at the three-digit ISCO level will not produce reliable estimates, since the sample sizes per occupation will be too low in many cases. Therefore, we use model-based SAE techniques in a hierarchical Bayesian framework to develop reliable estimates at this level. We take the unit-level model used by Bijlsma et al. (2017) and adjust it for our purposes, using the occupation level instead of the municipality level and adding extra occupation-specific regressors. The following is a summarized explanation of our model framework.

The basic idea of SAE is that we assume that our dependent variable (numeracy) is closely linked to personal characteristics found in both PIAAC and larger auxiliary data sets such as the LFS survey data and we use that data to obtain a synthetic estimate of hourly wages per occupation. The standard error of this estimate will be low, at the cost of introducing bias due to not taking into account the error term. We can then take a weighted average between the direct estimates from the PIAAC data and this synthetic estimate to arrive at more robust and reliable results while introducing only limited bias. A full explanation of the calculation of the weights and accounting for the PIAAC design structure is given by Bijlsma et al. (2017). 
Figure C1 A normal Q-Q plot of the estimates on numeracy per occupation for one-digit ISCO level (upper left), twodigit ISCO level (upper right) and three-digit ISCO level (bottom)
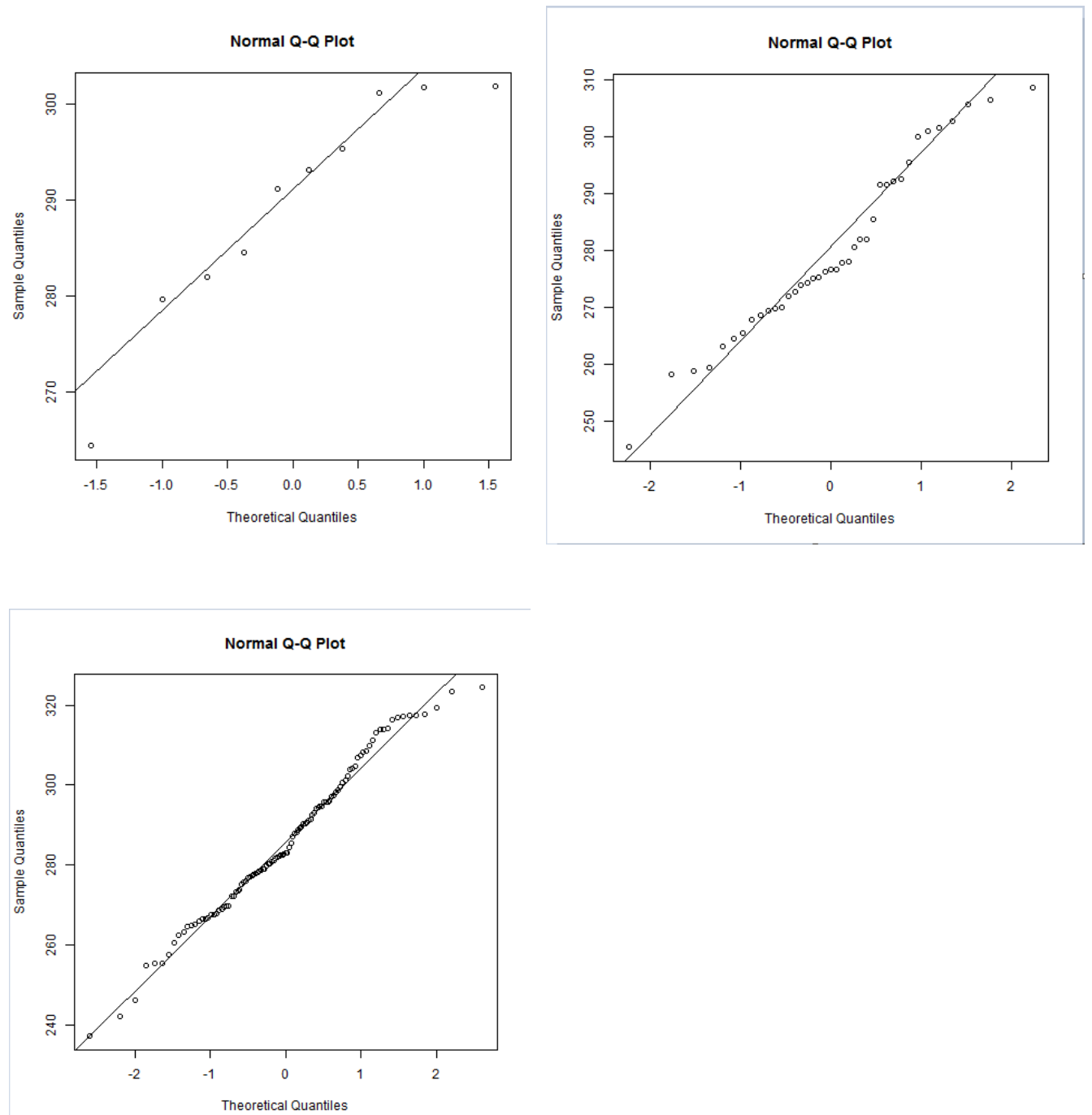
Figure C2 Comparison of standard errors of numeracy estimates within occupations for one-digit ISCO level (top), two-digit ISCO level (middle) and three-digit ISCO level (bottom)
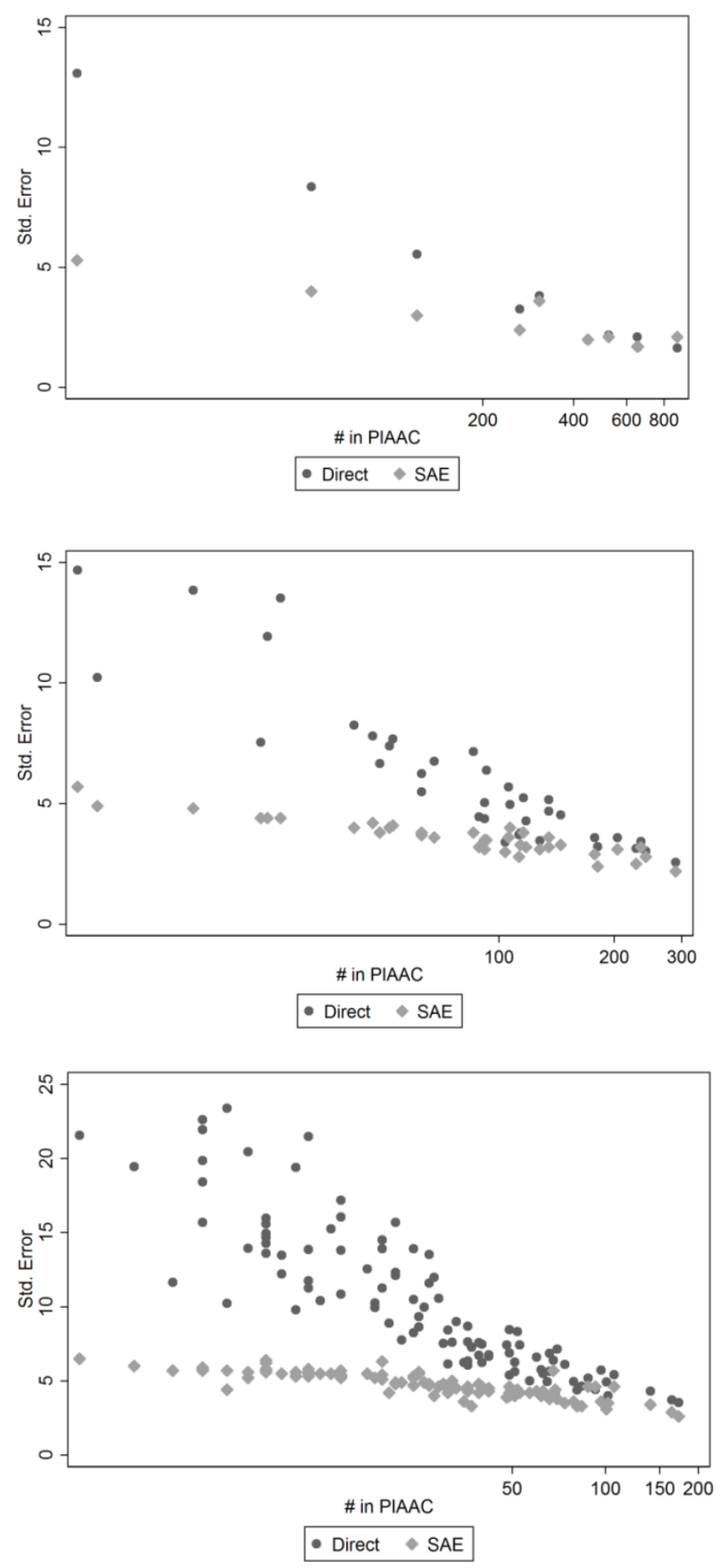